IZA DP No. 8230

Divorce, Abortion and Children's Sex Ratio:

The Impact of Divorce Reform in China

Ang Sun

Yaohui Zhao

May 2014 


\title{
Divorce, Abortion and Children's Sex Ratio: The Impact of Divorce Reform in China
}

\author{
Ang Sun \\ Renmin University of China \\ Yaohui Zhao \\ Peking University \\ and IZA
}

Discussion Paper No. 8230

May 2014

IZA

P.O. Box 7240

53072 Bonn

Germany

Phone: +49-228-3894-0

Fax: +49-228-3894-180

E-mail: iza@iza.org

Any opinions expressed here are those of the author(s) and not those of IZA. Research published in this series may include views on policy, but the institute itself takes no institutional policy positions. The IZA research network is committed to the IZA Guiding Principles of Research Integrity.

The Institute for the Study of Labor (IZA) in Bonn is a local and virtual international research center and a place of communication between science, politics and business. IZA is an independent nonprofit organization supported by Deutsche Post Foundation. The center is associated with the University of Bonn and offers a stimulating research environment through its international network, workshops and conferences, data service, project support, research visits and doctoral program. IZA engages in (i) original and internationally competitive research in all fields of labor economics, (ii) development of policy concepts, and (iii) dissemination of research results and concepts to the interested public.

IZA Discussion Papers often represent preliminary work and are circulated to encourage discussion. Citation of such a paper should account for its provisional character. A revised version may be available directly from the author. 


\section{ABSTRACT}

\section{Divorce, Abortion and Children's Sex Ratio: The Impact of Divorce Reform in China*}

This paper explores how the relative circumstances of men and women following marital dissolution affect sex-selection behavior within marriages. China's 2001 divorce reform liberalized divorce in favor of women and secured women's property rights after separation. We use this improvement in women's bargaining power in marriage for a regression discontinuity analysis of the demand for sex-selective abortions. We show that the increase in women's bargaining power reduces the propensity to have a son after a firstborn daughter by 8.9 percentage points. We also find that the effect is larger for women with higher health risks.

JEL Classification: D13, J12, J13, J16

Keywords: gender inequality, intra-household allocation, divorce law

Corresponding author:

Yaohui Zhao

China Center for Economic Research

Peking University

Beijing 100871

P. R. China

E-mail: yhzhao@ccer.pku.edu.cn

\footnotetext{
* The authors thank Andrew Foster, Anna Aizer, Vernon Henderson, Sriniketh Nagavarapu, Nancy Qian, and Anja Sautmann for very helpful suggestions on earlier versions of this paper. We also thank participants at the Applied Micro Lunch, Race and Inequality workshop at Brown University, NEUDC 2010, RES 2011 and CESI 2012 for useful comments. All mistakes are our own.
} 


\section{Introduction}

Household outcomes depend on decisions made by spouses who may often disagree. In these circumstances, the distribution of decision-making power may matter a great deal for intra-household allocation outcomes. Among these outcomes, gender inequality in the next generation of households is a topic of much interest among social scientists and policy makers. The most salient manifestation of persistent gender inequality is the phenomenon of "missing women" (Sen, 1990; 1992). This phenomenon refers to the smaller number of women than would be expected in the population if girls and women throughout the developing world were born and died at the same rate as boys and men. Today, among the estimated six million missing women, 23 percent were never born (Duflo, 2012). In this paper, we exploit China's 2001 divorce reform to investigate the effect of women's bargaining power within a household on sex-selective abortions and suggest a mechanism to explain our findings.

Besides "missing girls", a large and growing literature in economics has associated improvements in women's bargaining power with decreased disadvantages among daughters, in such dimensions as schooling, health and health care 1 Because some earlier work has suffered from problems of endogeneity (see Duflo (2003) for a detailed review), more-recent studies have examined the impact of certain exogenous shocks to women's income on children's wellbeing. ${ }^{2}$ However, these shocks increased both women's bargaining power and the relative return to having daughters (Qian, 2008) or the household's total income (Duflo, 2003). When children are regarded as household investment or consumption (Banerjee, 2004), the shocks to women's economic value cannot be used to rule out the unitary model of household decision making or to identify the effect of bargaining power on daughters' well-being.

A "cleaner" shock on bargaining power can be one that changes "extra

\footnotetext{
${ }^{1}$ Previous research shows that when women have more control over household income, the mortality rate for daughters decreases. For example, see Ben Porath (1967, 1973, 1976); Burgess and Zhuang (2000); Clark (2000); Duflo (2003); Das Gupta (1987); Foster and Rosenzweig (2001); Rholf, Reed and Yamada (2010); Rosenzweig and Schultz (1982); and Thomas, Strauss and Henriques (1991), to cite just a few.

${ }^{2}$ For example, Duflo (2003) uses the pension windfall for grandmothers in South Africa; Qian (2008) uses the increase in the tea price in China.
} 
household environmental parameters" (EEP) or "distribution factors" (Browning and Chiappori,1998). Because such a shock influences the decision-making process but not the budget constraint (or preferences), the resulting change in intra-household resource allocation points directly to diverging preferences between men and women. Legal innovations in the area of property division upon divorce satisfy such identification conditions because they affect the relative status at the "threat-point" or the "exit" of the marriage (Mansor and Brown, 1980; McElroy and Horney, 1981; McElroy, 1990) without changing household budget constraint. A large literature has provided empirical evidence that laws governing the division of property upon divorce have significant impacts on women's bargaining power in the household ${ }^{3}$ But this literature has not yet investigated the outcome of gender disparity among children in households.

China's 2001 divorce reform liberalized divorces in favor of women and secured women's property rights after separation. By improving women's outside option (welfare level in the event of relationship dissolution), the amendment effectively strengthened their status within their partnerships. Using this divorce reform for a regression discontinuity analysis on sex-selective abortion demand, we provide a rigorous identification of the impact of intra-household bargaining power on sex-selective abortions against girls.

Our main empirical analysis uses data from China's 2005 One-Percent Population Survey. We focus on the sex ratio of the second children following firstborn girls, because according to the prior literature, this is the margin at which sex-selective abortions are heavily used. We detect a discontinuous decline in the sex ratio (defined as the ratio of the number of boys to the number of girls) among the cohort conceived in February 2002, shortly after the de facto implementation of China's amended divorce law on December 26, 2001. During the brief period around the detected timing threshold of February 2002, the propensity to have a son after a firstborn daughter decreased by

\footnotetext{
${ }^{3}$ Prior empirical research has studied the impact of divorce law changes in countries such as the U.S., Canada and Brazil on such household outcomes as labor supply (Gray, 1998; Stevenson, 2008; Rangel, 2006; LaFortune et al., 2012); household specialization (Stevenson, 2008); domestic violence (Aizer, 2011; Stevenson and Wolfers, 2006); and children's wellbeing (Gruber 2004; Rangel 2006).
} 
8.9 percentage points. Our results are robust to standard regression discontinuity checks. We also review all policies that could potentially impact the incidence of sex-selective abortions in the relevant time window and rule them out as the primary driving force behind the decline in children's sex ratio. We offer supplementary evidence on the increase in children's caloric intake and the decrease in husbands' cigarette and liquor consumption, which are widely regarded in the literature as evidence of an improvement in women's bargaining power.

To interpret the effect of women's bargaining power on less missing girls, the previous literature implicitly assumes women's lesser prejudice against daughters. $4^{4}$ However, in countries with highly skewed sex ratios, such as China and India, it is plausible to cast skepticism on this assumption (Anold, Choe and Roy, 1998; Chu, 2001). Women's son preference may even be stronger because a son will bring them more respects from the husbands and in-laws as well as instrumental supports in their old age. While we do not aim to reject differential values attached to sons, in this paper we suggest a novel mechanism based on the observation of asymmetric health-related costs between the wife and husband upon sex-selective abortions. This distinction is meaningful because the implications from the model can be applied to other cases of household public-good provision, including those in which there is no clear gender difference in preferences.

We draw on the insights of non-transferable utility (Chiappori, Lyigun and Weiss, 2007) to demonstrate how these asymmetric costs can affect demand for sex-selective abortions. Specifically, bearing the lion's share of physical and psychological health-related costs of sex-selective abortions, the wife will demand compensation in terms of private consumption and the husband will face the tradeoff between sacrificing his private consumption and attaining a desirable sex composition of children. The amount of compensation upon abortion is determined by women's bargaining position. When the divorce reform

\footnotetext{
${ }^{4}$ The theoretical foundation can by formalized by the collective model laid out by Blundell, Chiappori and Meghir (2005), which focuses on the context of sharing one public good when one member's marginal willingness to pay is more income-sensitive; then, an improvement in this member's control of the family income will increase this public good expenditure.
} 
increased women's bargaining power, the husband found it more 'expensive' to make his wife accept sex-selective abortion and households on the margin will switch from abortion to non-abortion. We show that under nontransferability, the utility Pareto frontiers of abortion and non-abortion intersect, and the improvement in women's divorce options will reduce the wife's healthdamaging efforts toward public-good provision (i.e., sex-selective abortion in our context).

Note that the health-related costs on sex-selective abortions are higher for women of low fecundity or being pregnant in late age. Therefore, we use the gap between marriage and having the first child 5 as a proxy for women's health-related costs on sex-selective abortion during the second pregnancy after controlling women's age at marriage, schooling years and SES. These characteristics could capture the opportunity costs of having children and the initial bargaining power prior to the reform. We find that after the amended divorce law, a one-year delay in having the firstborn daughter results in an extra 2.6-percentage-point reduction in the probability of having a secondborn son.

The paper is organized as follows: In Section 2, we describe the background of China's widespread sex-selective abortions and the 2001 divorce reform. In Section 3, we present the theoretical model and derive the predictions on the less-skewed sex ratio caused by the divorce reform and larger effect of the reform among women with higher health-related costs. In Section 4, we establish the causal link between divorce reform and the decline in children's sex ratio and present the RD estimands. In Section 5, we explore the heterogeneity in the magnitude of the effect across women with different health-related costs to shed light on the mechanism of the effect. In Section 6, we conduct robustness checks and provide supplementary evidence. Finally, Section 7 presents concluding remarks.

\footnotetext{
${ }^{5}$ Sturm and Zhang (1993) use first conception interval as a measure of fecundibility.
} 


\section{Sex-Selective abortions and Divorce in China}

\subsection{Sex-Selective Abortions}

Under the restrictive family-planning policy in China, induced abortion following ultrasound B sex screening is the most common form of sex selection (Ebenstein, 2008; Li, 2007; Li, Wei and Feldman, 2005;Zeng, 1993). The stipulations also prevent individuals from using divorce to evade the familyplanning policy: remarried couples qualify to have a child of their own only when one party does not already have a child and the other does not have more than one. 6

In rural areas, six provinces apply the restrictive one-child rule and a significant amount of fine will be charged for a second birth (Scharping, 2003); five provinces generally allow two births; and 19 other provinces apply the "Girl Exception" or the so-called "1-Son-2-Children" policy, meaning that if the firstborn is a daughter, a couple can have another child. But a couple is generally not allowed to have more than two children. Sex-selective abortions are seldom used for the first birth but heavily used for the second pregnancy after a firstborn daughter (Ebenstein, 2008; Li, 2007; Li, Wei and Feldman, 2005; $\mathrm{Li}, 2007)$. Therefore, in this paper, we focus on the sex of the second-born child after having a firstborn daughter.

Sex-selective abortions inevitably harm women's physical and, especially, psychological health. The sex of a fetus is usually detected during the second trimester or later. An abortion in that period, in comparison to a firsttrimester abortion, requires higher doses of the drug Misoprostol to induce labor; in addition, the surgery takes longer, and there are more side effects. In the 1997 Survey of Population and Reproductive Health in China, 75.46 percent of women stated that abortion had a negative impact on their physical and psychological health, with 18.58 percent rating the impact as major.

\footnotetext{
${ }^{6}$ The restriction was relaxed somewhat in a few provinces after our study period, since 2008.
} 


\subsection{Divorce: The Status Quo and the New Divorce Law}

In rural China, the divorce rate, on average, is traditionally low (Zeng and Wu, 2000). In our 0.1- percent sample from the 2000 Population Census and the 25-percent sample from the 2005 One-Percent Population Survey, there were only 3.62 and 3.78 divorces per 100 marriages among women between ages 25 and 35 in 2000 and 2005, respectively ${ }^{7}$ The divorce rate is higher among younger couples and in cities.

The main reason for the low divorce rate in rural areas is that women have poor divorce options. The village generally supplies land and homestead through the husband's family, and women forfeit these properties upon divorce. Parents treat a married daughter as "water poured out" and, thus, usually do not welcome her back. In a case study by Chan and Liu (2000), the researchers record that women who would like to divorce but endure their unhappy marriages assume that, were they to leave their marriages, they would face an immediate loss of housing and finances.

The amended divorce law was announced on April 28, 2001, and the judicial interpretation of the amendment, which serves as an operational guideline for implementing the reform, was issued on December 26, 2001. The new divorce law specified property division in greater details, specifically restating rural women's rights to land and housing upon divorce. Women's property rights had been announced before this amendment, but this reform added new articles to improve enforcement 8 Moreover, the guidelines for implementation made it clear that if after divorce, the wife were unable to maintain a basic standard of living according to the properties entitled upon divorce, the husband would be responsible for compensating her to that standard. In particular, the wife would be regarded as not meeting the "basic living standard" if she did not have a place to live.

\footnotetext{
${ }^{7}$ In both datasets, marital status is reported with the following choices: married, remarried, divorced, widowed and never married. We define divorce as including remarriages. Because we restrict the sample to ages 25-35, remarriage after widowhood is rare in the data.

${ }^{8}$ Article 47: "During the divorce proceedings, if one party attempts to conceal, transfer, sell or destroy community property, or falsify liability with the intention of misappropriating the other party's property, when property is partitioned in court, the court may award to the party at fault either a smaller amount of property or none at all."
} 
Another important amendment of this divorce law is that it makes unilateral divorce possible in the case of domestic violence and extra-marital relationships, which are grounds used mainly by women. The new law also stipulates that when a divorce is granted, the innocent party can now seek damages from the guilty party $!^{9}$

\section{The Model}

\subsection{Basic Setup}

To better understand the interplay between children's sex ratio and women's divorce options, we consider a simple theoretical framework with public-good provision in the household ${ }^{10} \mathrm{We}$ assume that both spouses place the same value, $\eta$, on the public good, the sex composition of children. We focus on households that are about to have a second child, given that the first is a girl. Assume that a firstborn daughter brings utility $\sigma$. For simplicity, assume that a second daughter does not improve the spouses' utility. $\gamma$ is the utility level of having a second-born son. Therefore, $\eta \in\{\sigma, \gamma\} . \gamma>\sigma$, indicates the preference for sons. We denote the husband's utility within marriage by $u$ and the wife's utility within marriage by $v$ :

$$
\begin{aligned}
u & =x_{H}+\eta \\
v & =\frac{x_{W}}{e}+\eta
\end{aligned}
$$

where $x_{H}$ and $x_{W}$ are the private consumption of the husband and wife, respectively. $e$ is the effort that the wife extends to increase the chance of having a son, $e \in\left\{e_{A}, e_{N A} \mid e_{A}>e_{N A}>1\right\}$. $e_{N A}$ and $e_{A}$ represent efforts without and with sex-selective abortion, respectively. Assuming that the natural probability of having a son is 0.5 in each pregnancy, $E \eta=0.75 \gamma+0.25 \sigma$ if $e=e_{A}$,

\footnotetext{
${ }^{9}$ For stipulations on damage compensation for domestic violence, see Article 46 (3) and (4), and for the damage compensation for bigamy and extra-marital relationships, see Article $46(1)$.

${ }^{10}$ We assume away unwanted pregnancies and inefficiencies generated by frictions or asymmetric information between the spouses.
} 
while $E \eta=0.5 \gamma+0.5 \sigma$ if $e=e_{N A}$.

Note that the utility within marriage is not transferable between the spouses. Specifically, the effort $e$ to provide public good will change the marginal rate of substitution between the husband's and the wife's private consumption, implying different slopes for the linear utility Pareto frontiers upon abortion and non-abortion. The specific utility function can be generalized to any utility that satisfies $\frac{\partial}{\partial e}\left(\frac{\partial v}{\partial x_{W}}\right)<0$ and $\frac{\partial}{\partial e}\left(\frac{\partial v}{\partial x_{H}}\right)=0$, where the effort level $e$ exerted by the wife depreciates her marginal utility of private consumption while the husband's remains intact or less affected. 11

We assume that the husband makes decisions about sex-selective abortion and consumption division, and the wife can reject his arrangements ${ }^{12}$ If she rejects them, divorce will be granted, and she will receive her reservation utility, $v_{d}-c_{W}$. The cost of divorce for spouse $i$ is $c_{i}, i=\{H, W\}$, which is determined by the legal environment or the so-called "extra-household environmental parameters" (Browning and Chiappori, 1998). In the case of this article, $c_{i}$ reflects the disutility from forfeiting entitled property and the costs of going through legal procedures to get divorced. $v_{d}$ describes the best divorce options for the wife, which are determined by her intrinsic characteristics (such as personality and looks) and follow a distribution with density $f\left(v_{d}\right)$. The wife rejects her husband's choice if $v<v_{d}-c_{W}$. The effect of the divorce law is formalized as decreasing in $c_{W}{ }^{13}$

\footnotetext{
${ }^{11}$ The assumption on utility can be further relaxed to satisfy the condition $\frac{\partial}{\partial e}\left(\frac{\partial v}{\partial x_{W}}\right)<$ $\frac{\partial}{\partial e}\left(\frac{\partial v}{\partial x_{H}}\right)$.

${ }^{12}$ The assumption does not contradict the patriarchal tradition in rural China. In addition, the intuition of the model applies to other methods of surplus division that set up a monotone positive relationship between the wife's utility within marriage and upon divorce.

${ }^{13}$ More generally, when the wife rejects the arrangements, divorce is granted with probability $\alpha$. When divorce cannot be attained, the wife's within-marriage utility could be lower than her reservation utility upon divorce. The husband will satisfy the wife to the level of utility upon divorce only if $\alpha$ and $c_{H}$ are large enough. The amended divorce law could also cause an increase in $\alpha$ to make divorce a more relevant "threat." The intuition in the analysis of the decrease in $c_{W}$ applies to the scenario of an increase in $\alpha$.
} 


\subsection{Solving the Household Optimization Problem}

The budget constraint of a representative household is:

$$
x_{H}+x_{W} \leq M
$$

where $M$ is the household income. We assume away the monetary costs of ultrasound B sex screening and induced abortions, as they are very low and insignificant for most couples.

The analysis starts when a couple has a firstborn daughter, and the fetus of their second pregnancy is revealed to be female. The husband makes the decision regarding sex-selective abortion. If he decides that the fetus should be aborted, he needs to raise the wife's private consumption so that she will receive her reservation utility, which equals her utility upon divorce. The payoffs for the husband in all contingencies are calculated as follows:

- $u^{N A}=M-\left(v_{d}-c_{W}-\sigma\right) e_{N A}+\sigma$, if the wife does not have a sex-selective abortion;

- $E u^{A}=M-\left(v_{d}-c_{W}-\frac{\gamma+\sigma}{2}\right) e_{A}+\frac{\gamma+\sigma}{2}$, if the wife has an induced abortion.

If the husband's payoff upon non-abortion, $u^{N A}$, is greater than the expected payoff upon abortion, $E u^{A}$, the household chooses non-abortion and has a daughter. Otherwise, the household chooses abortion and having a son with probability 0.5 .

[Figure IA is here]

Figure IA depicts the utility Pareto frontier (UPF) upon abortion and non-abortion. The horizontal axis is the wife's utility within marriage, which equals the reservation utility upon divorce; $E u^{A}\left(v_{d}\right)$ has a higher slope than $u^{N A}\left(v^{d}\right)$ because it is more expensive to compensate the wife to $v_{d}-c_{W}$ when the wife exerts more effort to have a sex-selective abortion. Lines $E u^{A}\left(v_{d}\right)$ and $u^{N A}\left(v^{d}\right)$ will intersect if $e_{A}$ is large enough compared to $e_{N A}$. That is, $e_{A}>\frac{2 M+\gamma+\sigma}{2 M+2 \sigma-(\gamma-\sigma) e_{N A}} e_{N A}$. Denote the value of $v_{d}$ at the intersection of lines $E u^{A}\left(v_{d}\right)$ and $u^{N A}\left(v^{d}\right)$ as $\hat{v}, \hat{v}=c_{W}+\frac{(\gamma+\sigma) e_{A}-2 \sigma e_{N A}+\gamma-\sigma}{2\left(e_{A}-e_{N A}\right)}$. 
In Figure IA, if $v_{d}<\hat{v}$, the UPF upon abortion $\left(E u^{A}\left(v_{d}\right)\right)$ falls outside that upon non-abortion $\left(u^{N A}\left(v^{d}\right)\right)$, and such a household should choose abortion; when $v_{d}>\hat{v}$, the UPF upon abortion $\left(E u^{A}\left(v_{d}\right)\right)$ falls inside that upon nonabortion $\left(u^{N A}\left(v^{d}\right)\right)$, and such a household should choose non-abortion.

\subsection{Comparative statics and main predictions}

The amended divorce law causes a decrease in $c_{W}$. Since

$$
\frac{\partial \hat{v}}{\partial c_{W}}>0
$$

, as $c_{W}$ decreases, the cutoff value of $v^{d}$ decreases. Given women's intrinsic divorce option distribution $f\left(v_{d}\right)$, there will be households shifting from abortion to non-abortion. In Figure I.A, the intersection (together with the UPFs) shifts left relative to $f\left(v_{d}\right)$ [1] Households with $v_{d}$ around cutoff $\hat{v}$ will shift from abortion to non-abortion. We state this in the proposition, as follows:

Proposition 1 The incidence of sex-selective abortion decreases with the improvement in women's divorce options.

To understand the intuition of this proposition, note that the husband faces the tradeoff between sacrificing more private consumption (the marginal cost is $\left.\left(v_{d}-c_{W}-\sigma\right)\left(e_{A}-e_{N A}\right)-0.5 e_{A}(\gamma-\sigma)\right)$ and having a more preferable sex composition of children (the marginal benefit is $0.5 e_{A}(\gamma-\sigma)$ ). The increase in $v_{d}-c_{W}$ increases the marginal cost of sex-selective abortion for the husband, and he could switch from choosing abortion to choosing non-abortion.

[Figure IB is about here]

To derive an additional testable prediction of the model, we consider variations in the level of effort required for abortion, $e_{A}$, in relation to non-abortion $e_{N A}$. We relax the prior assumption and allow for $e_{A}<\frac{2 M+\gamma+\sigma}{2 M+2 \sigma-(\gamma-\sigma) e_{N A}} e_{N A}$. This situation is illustrated in Figure I.B, where the UPFs of abortion and non-abortion, $E u^{A}\left(v_{d}\right)$ and $u^{N A}\left(v_{d}\right)$, do not intersect, and the UPF of abortion dominates that of non-abortion. The comparison between Figure I.A and

\footnotetext{
${ }^{14}$ Equivalently, given the position of the UPFs, in Figure I.A, the decrease in $c_{W}$ can be regarded as shifting the distribution $f\left(v_{d}\right)$ rightward.
} 
I.B underscores the importance of the wife's health-related costs in decision making upon sex-selective abortions.

Corollary 1 All else equal, women with a larger $e_{A}$ relative to $e_{N A}$ are more likely to respond to the improved divorce options, and household demand for sex-selective abortions in such families is likely to decrease.

\section{Data and Regression Discontinuity Estima- tion}

\subsection{Data and Graphical Findings}

The empirical analysis of this study compares the sex ratio of the second children following firstborn girls shortly before and after the de facto enactment of the amended divorce law.

The empirical analysis of children's sex ratio uses the 25-percent sample of the 2005 One-Percent Population Survey. The Survey contains questions on sex, date of birth, marital status, date of first marriage, educational attainment, migration, and relationship to the head of household. The sample is limited to the second birth, conditional on a firstborn daughter, with rural residency status (hukou). We further confine the sample to couples married before the divorce law amendment to avoid the potential complication that the law could affect intra-household allocation through affecting marriage matching (Lafortune et al., 2012).

Table I summarizes the descriptive statistics on the ratio of male births after a firstborn girl and the personal characteristics of the couple. In Figure II.A, we categorize children into different cohorts by the timing of conception (nine months before birth) and compare the sex ratio of cohorts conceived before and after the implementation of the new divorce law. Sex ratio is defined as the number of boys to the number of girls. Figure II.A reports the sample mean of sex ratio by cohort. Each cohort is defined as all babies conceived in each six-month period following February 1997. As is evident from Figure IIA, within the data period, we observe a marked decline in children's sex ratio, 
down from a high point of 2.4 for babies conceived between August 1998 and January 1999 to a low point of 1.7 for conceptions between February and July 2004. The red line marks the cohort conceived between February and July 2002, which is where the sharp decline takes place.

[Table I is here]

[Figure II.A is here]

To estimate the significance level of this decline in Figure II.A, we fit the following OLS regression:

$$
\text { Male }_{i c}=\alpha+\sum_{l=1}^{15} 1[c=l] \beta_{l}+X_{i c} \gamma+\lambda+\varepsilon_{i c}
$$

The dependent variable is a dummy indicator of whether child $i$ is male. Male $=1$ if the child is male, 0 otherwise. Each $l$ represents a cohort in Figure II.A. $X_{i c}$ is the vector of control variables, including the parental characteristics listed in Table 1. $\lambda$ is the province fixed effect. The first cohort in Figure II.A (i.e., the cohort conceived between February and July 1997) is the reference group.

The empirical results of equation (1) are shown in Figure II.B. The circles are the coefficients of the cohort indicators, with the magnitude labeled in the figure. The lines are the 95-percent confidence interval. In Figure II.B, the 95-percent confidence intervals start to be consistently below 0 from the cohort conceived during the six-month period between February and July 2002. The decline in the propensity to have a second-born son after a firstborn daughter is about six percentage points, meaning that the sex ratio has declined from 2.3-2.3 boys to one girl to 1.56-1.6 boys to one girl since the reform's implementation, holding other factors constant.

[Figure II.B is here]

\subsection{Graphical Evidence on Causal Relationship}

Figures II.A and II.B show that a sharp decline appears at the cohort that was conceived during the six-month period between February and July 2002. The sharp decline within a short time period seems to suggest a discrete change in 
the sex ratio (or a break in the trend) shortly after the implementation of the divorce reform at the end of December 2001. In other words, the graphical descriptions indicate a clear timing threshold from which the sex ratio started to be affected. If such a timing threshold exists, and if it is consistent with that of the divorce reform implementation, it will be credible to establish a causal link between the reform and a more-balanced sex ratio. Moreover, we will be able to apply a more rigorous study design of regression discontinuity (RD) to estimate the effect of divorce reform at the timing threshold. The RD estimand can be regarded as a lower bound of the divorce reform's effect because given a longer period of time, more households could be able to respond to the intervention.

We apply an exercise by Chay, McEwan, and Urquiola (2005) to look for the conception-timing threshold. As previously mentioned, the divorce law amendment was announced on April 28, 2001 and the judicial interpretation on December 26, 2001. The dissemination and assimilation of the information took time; thus, the de facto timing threshold when households started to respond to the amendment is known with error. We run 92 regressions in total. Each includes a different indicator of "conceived in month $l$ or after," where $l$ represents the exact month of conception during the 93 months between August 1997 and May 2004. The regression is as follows:

$$
\text { Male }_{i c}=\alpha+1[c \geq l] \beta_{l}+X_{i c} \gamma+\lambda+\varepsilon_{i c}
$$

with all other features similar to those in equation (1).

Suppose that there exists a clear timing threshold at conception time $l^{*}$, when the sex ratio started to be affected. The correlation between the sex ratio and the proxy variable should be the strongest in the regression with the dummy indicator $1\left[c \geq l^{*}\right]$, and, therefore, $\beta_{l^{*}}$ has the largest magnitude of $t$-ratio compared with that in regressions using other cutoff indicators. In addition, the adjusted $R$-squared should peak in the regression where the magnitude of the $t$-ratio yields the maximum. Moreover, we should be able to observe a "concave" pattern for both the sequence of the magnitude of $t$-ratios and the adjusted $R$-squared. This is because the farther away the assumed 
cutoff is from the real timing threshold $l^{*}$, the weaker are the explanatory power of that assumed cutoff and the correlation between that cutoff and the sex ratio. Note that if the magnitudes of the adjusted $R$-squared and the $t$-ratio show a concave pattern, we can rule out a common time trend of the sex ratio. If the detected timing threshold of conception matches the timing of the new law's implementation, we can to a large extent rule out the effects of other policies.

We graph the adjusted $R$-squared of the sequence of regressions and the $t$-ratio magnitude of the coefficient of dummy indicator "conceived in month $l$ or later" in Figures III.A and III.B.

[Figure III.A is here]

[Figure III.B is here]

As the figures show, the magnitudes of the adjusted $R$-squared and the $t$-ratio of the coefficient of the threshold peak in the same regression when using the conception timing February 2002 as the cutoff in equation (2). The adjusted $R$-squared and the $t$-ratio not only attain maximum magnitude in the regression using February 2002 as the cutoff, but the magnitudes of the $R$-squared and the $t$-ratio also show a "concave" pattern. Specifically, in Figure III.A, the adjusted $R$-squared increases when the cutoff approaches the threshold February 2002, and it decreases when the cutoff is defined as an earlier or later date. The adjusted $R$-squared gets smaller because more "noise" is added to the "real" threshold. A similar pattern is observed in Figure III.B when examining the magnitude of $t$-ratio of the sequence of the cutoffs' coefficients.

The threshold is, to a large extent, consistent with the timing of the implementation of the divorce law. In addition, the "concave pattern" shows that it is unlikely that a time trend is driving the decline in children's sex ratio.

\subsection{Regression Discontinuity Estimation}

To identify the effect of the divorce reform, with the timing threshold detected, we adopt a reduced-form non-parametric RD design. In this design, the jump in the regression of the dummy variable indicating whether the child is male 
(denoted by male in (3)) on the timing of the mother's conception (denoted by $c$ in (3)) is interpreted as an average causal effect of the treatment (Imbens and Lemieux, 2008). Formally, the estimand is

$$
\tau_{R D}=\lim _{c \uparrow l^{*}} E\left[\text { male }_{i} \mid c_{i}=l^{*}\right]-\lim _{c \downarrow l^{*}} E\left[\text { male }_{i} \mid c_{i}=l^{*}\right]
$$

We use local linear regression to calculate $\lim _{c \downarrow l l^{*}} E\left[\right.$ male $\left._{i} \mid c_{i}=l^{*}\right]$ and $\lim _{c \uparrow^{*}} E\left[\right.$ male $\left._{i} \mid c_{i}=l^{*}\right]$, respectively. For the implementation of local linear regression, we calculate the robust confidence intervals by the method proposed in Calonico, Cattaneo and Titiunik (2013a) and use a triangular kernel to attach more weight to observations closer to the timing threshold. We also use, for comparison, the bandwidth by the method proposed by Imbens and Kalyanaraman (2012) and Imbens and Lemieux (2008).

The advantage of the local linear regression above is that this non-parametric method does not need to impose assumptions on the functional form of how male $_{i}$ depends on the running variable $c_{i}$. However, the disadvantage is that only observations within the optimal bandwidth are used for estimation, which causes efficiency loss and prevents us from detecting significant jump at the threshold. While we prefer the nonparametric estimands concerning consistency, as a robustness check, we use all children conceived between February 1996 and February 2005 and employ an alternative parametric method, by modeling the outcome male $_{i}$ as

$$
\text { male }_{i}=\alpha+1\left[c_{i} \geq l^{*}\right] \beta+f\left(c_{i}-l^{*}\right) \delta+1\left[c_{i} \geq l^{*}\right] \cdot f\left(c_{i}-l^{*}\right) \phi+\varepsilon_{i}
$$

where $f\left(c_{i}-l^{*}\right)$ is a polynomial function of the time relative to the threshold $l^{*}$. We employ second-, third-, and quadratic-polynomial control functions, respectively.

In addition to investigating the child's gender directly, we examine whether birth spacing gets closer for households that have two children, the first being a daughter. Ebenstein (2008), using a sample from China's 2000 Population Census, finds that the birth spacing between children is significantly longer if the second birth is a son. Pörtner (2010) uses a similar strategy to detect sex-selective abortions in India. 
[Figure IV is here]

[Table II is here]

Figure IV plots the probability that the second child after a firstborn daughter is a son, according to the mother's conception month relative to the timing threshold ( $=0$ if the child is conceived in February 2002). The circles are the average of the dummy indicator of being a son for groups of children, defined by the conception months relative to the threshold February 2002. In addition, we present the smoothed values from a kernel-weighted local polynomial regression of the dummy indicator of the second child being a son on the relative month at the left and right side of the cutoff, respectively. Together, we plot the 95-percent confidence band. Figure IV shows the drop-off of the dummy indicator for the child being a son at the time when the divorce reform took effect.

Table II, Columns (1)-(3) report the estimands using different bandwidth selectors, showing that the decrease at the timing cutoff is consistently significant at the one-percent level. When the bandwidth is confined to the nine months around the threshold, the decline in the propensity to have a son after a firstborn girl amounts to 8.9 percentage points. Columns (4)-(6) report the OLS estimation with second-, third- and fourth-order polynomial control functions, respectively. The entries show that the jump at the threshold is significant at the five-percent level.

[Figure $\mathrm{V}$ is here]

[Table III is here]

Figure $\mathrm{V}$ plots birth spacing between the first and second child against mother's relative conception month. The circles are the average of birth spacing in each conception month. The curves are the smoothed values from a kernel-weighted local polynomial regression of the birth spacing on the relative month at the left and right side of the cutoff, respectively. The entries in Table III, Columns (1)-(3) report that the estimands using different bandwidth selectors are significant at the five-percent level. Within the bandwidth of eleven months around the threshold, birth spacing decreased by 3.386 months, which is comparable to the estimand by Ebeinstein (2008). Using the whole sample comprised of all second-born children conceived after February 1996, Columns 
(4)-(6) show the OLS estimation with different-order polynomial control functions.

The validity of our RD design depends crucially on the continuity of the running variable - i.e., cohort measured in conception month in our RD design. The concern about validity is raised by the suspicion that women may want to delay pregnancy until being exposed to the divorce reform. In this paper, we adopt McCrary (2008) density test ${ }^{15}$ to formally examine whether the density of the cohort is continuous at the threshold February 2002. The outcome of this test is presented in Figure VI, and the null of continuity is not rejected.

[Figure VI is here]

The identification assumption in (3) is that the cohorts that conceived shortly before and after the timing threshold, when the new divorce law took effect, are comparable except for the exposure to the new divorce law. Specifically, two assumptions must hold. First, the (unobserved) household resources and characteristics that influence outcomes must have "continuous" effects on demand for sex-selective abortions. Second, these household resources and characteristics should have continuous distributions around the timing threshold. We provide suggestive evidence that the unobservable household characteristics are likely balanced within a small neighborhood around the threshold, to the extent that the observable pre-determined covariates do not show any significant jump at the cutoff, February 2002. Figure VII shows graphical evidence.

[Figure VII is here]

To interpret the result from (3), we need to impose the assumption of monotonicity. Specifically, the effect we investigate is how divorce reform impacts the incidence of subsequent sex-selective abortion for "compliers"defined as mothers who have a sex-selective abortion if they conceive a baby before the divorce reform took effect (before February 2002), and do not if they conceive a baby after the divorce reform took effect (February 2002 or

\footnotetext{
${ }^{15}$ The test is to smooth a finely-gridded histogram using local linear regression, separately on either side of the cutoff, and to conduct a Wald test of the null hypothesis that the discontinuity is zero.
} 
later). Then,

$$
\begin{aligned}
\tau_{R D} & =\lim _{c \downarrow l^{*}} E\left[\text { male }_{i} \mid c_{i}=l^{*}\right]-\lim _{c \uparrow l^{*}} E\left[\text { male }_{i} \mid c_{i}=l^{*}\right] \\
& =E\left[\text { male }_{i}(1)-\text { male }_{i}(0) \mid i \text { is a complier and } c_{i}=l^{*}\right]
\end{aligned}
$$

where male $_{i}(1)$ denotes the child $i$ 's sex when the mother's conception happened after the timing threshold, and male $e_{i}(0)$ denotes the child $i$ 's sex when the mother's conception happened before the timing threshold. In addition, we regard $E\left[\right.$ male $_{i}(1)-$ male $_{i}(0) \mid i$ is a complier and $\left.c_{i}=l^{*}\right]$ as the lower bound of the divorce reform's average effect because information about the reform is likely to reach more households and be better understood later (when $l>l^{*}$ ).

Another concern regarding the interpretation is that the analysis of children's gender uses information on surviving children reported by their parents. This sex ratio could be different from the sex ratio at birth because the decline in the former may also be driven by the decreasing gender difference in the mortality rates for young children, or by the decreasing propensity to underreport female births. Much of the previous research shows that the skewed sex ratio of children is caused mainly by sex-selective abortions. Zeng (1993) rules out the likelihood of infanticide using data from multiple sources. Goodkind (2011) analyzes China's 2000 Census data and finds that given excess underreporting of young daughters, especially pronounced just after 1990, estimated sex ratios are lower than reported ratios ${ }^{16}$ We find no nationwide policies in the relevant time window that could have caused a systematic decrease in underreporting female births. We also find no factors that would mitigate the misreporting incentive, specifically for children conceived after the detected timing threshold. One concern is that, if there is a secular trend or life-cycle pattern of such underreporting, our RD estimands could be contaminated if the RD design fails to drop it out, especially when the bandwidth is large. However, Zeng (1993) finds that underreporting of female children is more common for newborns or very young children because 'hiding' a child will be more costly as she grows older. In this article, we find that the sex ratio is

\footnotetext{
${ }^{16}$ Goodkind (2011) finds that China's sex ratio at birth, once it is standardized by birth order, fell between 2000 and 2005, which is consistent with our findings.
} 
more balanced among younger cohorts, which could only be underestimated if underreporting female children could possibly affect the RD estimand.

\section{Heterogeneity across Women with Different Health-related Costs}

To investigate the heterogeneity described in Corollary 1, we fit the following regression function:

$y_{i c}=\alpha+\sum_{l=1}^{15} 1[c=l] \times I N T E R V A L_{i c} \cdot \omega_{l}+\sum_{l=1}^{15} 1[c=l] \beta_{l}+I N T E R V A L_{i c} \theta+X_{i c} \gamma+\lambda+\varepsilon_{i c}$

In equation (6), INTERVAL $L_{i c}$ is defined as the period between women's first marriage and having her first child for woman $i$, whose second child is in cohort $c . X_{i c}$ is a series of control variables that we will discuss in more details. $\lambda$ is provincial fixed effects. If women who get pregnant at a later age have a high cost of sex-selective abortion, $\omega_{l}$ should be negative when $l>l^{*}$.

We use the interval between women's first marriage and having her first child as a proxy variable for woman $i$ 's health-related costs of sex-selective abortion. It is calculated using the timing of the first marriage and that of the firstborn child in the 2005 Population Survey. Under the patriarchal tradition in rural China, couples generally start trying to have a child right after getting married. Moreover, sex-selective abortion is seldom used during a first pregnancy, a fact that is supported by much of the previous research (Li, Wei and Feldman, 2005; Li, 2007). Therefore, the interval between the first marriage and having the first child is more likely to be determined by fecundity or some exogenous factors. In prior research, Sturm and Zhang (1993) also use first conception interval as a measure of fecundibility. Women with a longer interval between marriage and the birth of their first child should have higher health-related costs for sex-selective abortions during the second pregnancy because they are more likely to have their second pregnancy in late age ${ }^{17}$ or because of their low fecundity.We discuss the validity of this

\footnotetext{
${ }^{17}$ There is considerable medical evidence that women's risk and health-related issues of
} 
proxy variable from three aspects. First, the interval between marriage and first birth may not capture only fecundity. If women with a better bargaining position tend to have their first child late and are closer to the margin to be affected by the divorce reform, then the negative correlation between the length of the interval and the magnitude of the divorce reform's effect can be explained by the difference in initial bargaining power. Second, fecundity could be the consequence of marriage matching if women's fecundity can be observed in marriage market or is closely related with observable factors valued in marriage market. Therefore, a household with a fertile wife may not be perfectly comparable to that with a less-fertile wife. Third, fecundity, per se, could affect women's bargaining position within a household.

We address these related concerns in a few ways. First, we control variables that could capture initial bargaining power and matching quality, including the education and age at the time of first marriage for both spouses. In particular, since women's age at first marriage is generally regarded as a strong indicator of bargaining position, to address the concern that the heterogeneity could be driven by the difference in initial bargarning position, we also control the interactions of age at first marriage and the dummy indicator of having a second child after the divorce reform. Second, we exclude the individual with the longest quartile of this interval. The intervals in the top quartile are longer than four years. We may suspect that for these women, the timing of having their first child could be a consequence of optimizing the trajectory of their career development, or they may not make a good comparison with those who have their first child soon after marriage. Finally, we argue that if low fecundity causes a decrease in women's bargaining position, the heterogeneity proposed in the model will be underestimated.

[Table IV and Table $\mathrm{V}$ are here]

Table IV, Columns (1)-(3) report the results of the specification of controlling provincial fixed effects, adding more controls for parental education, ethnicity, age at first marriage and indicators of migrants, respectively. Prior

pregnancy and sex-selective abortion increase with the age at which she becomes pregnant. Complications include elevated blood pressure, gestational diabetes, premature labor, and bleeding disorders such as placental abruption, etc. 
research (Bates et al., 2004; Field and Ambrus 2008) show that women's education levels and age at marriage are likely to be associated with their position in the marriage. Parents' migration status could potentially affect sex selection because some migration could be driven by the incentive to escape from the restrictions of their local family-planning policies. Table IV shows that women who are older at first pregnancy are less likely than those who are younger to have a second-born son after having a firstborn daughter. Specifically, a oneyear increase in the interval between marriage and the first birth decreases the probability of having a second-born son by 1.5 to 2.4 percentage points. This is consistent with Corollary 1, in that households become more responsive to the divorce law when women's health-related costs of sex-selective abortions are large enough. This is the case because the couple will not make a (joint) decision to exert a costly effort when it sacrifices too much of the husband's private consumption.

In Column (4), we confine the sample to women whose time between their first marriage and having their first child is shorter than four years, the 75th percentile. By focusing on this subsample, we exclude, to an extent, those who intend to delay having children. The coefficients are of similar magnitudes and similar significance levels. The robustness of the result shown in column (4) suggests that the variation in the time interval that we use for identification is largely exogenous. Specifically, it is unlikely to be driven by women's optimization or to be related to women's bargaining power.

Regarding the outcome of birth spacing, the first three columns of Table $\mathrm{V}$ show that birth spacing decreases by around 0.4-0.6 months following the divorce reform when the woman's age when having her first child increases by one year. The coefficients are of similar magnitude when the sample is confined to women with a shorter time span between their first marriage and having their first child (column (4)). 


\section{Robustness and Supplementary Results}

\subsection{Other Policies}

To exclude the possibility that policies other than the new divorce law could drive the discrete change in children's sex and induced abortions, we conduct an exhaustive search of all policy changes in the relevant time window.

In December 2001, the central government announced that the "Law of Population and Family Planning" (LPFP) was to replace the previous "Regulation of Population and Family Planning" to govern family planning. The contents of the two documents are essentially the same, except that the LPFP is enforceable by the court. 18 Nevertheless, some skepticism is warranted because a law generally means stricter enforcement than a policy, and our detected timing threshold is close to the timing of the LPFP announcement. Therefore, we examine whether the LPFP caused the discontinuity.

Unlike the divorce reform, which took effect nationwide immediately following its enactment, due to large preexisting differences in family-planning policies across provinces, LPFP let each province decide on the timing and specifics of a local policy change relative to its original family-planning policy. Consequently, the implementation took place between September 2002 and April 2004 (See Appendix Table I), a period that was after our discontinuity threshold. To show that the discrete change in the sex ratio should not be attributed to LPFP, we conduct a discontinuity analysis by plotting children's sex ratio against the conception month relative to the implementation dates on left and right side of the implementation cutoff, respectively. Figure VIII clearly shows that there is no discontinuity at the time of the enactment of the provincial Act of Population and Family Planning.

\footnotetext{
${ }^{18}$ The "Act of Population and Family Planning" has been slightly changed in some provinces. For example, in Hubei province, the 1987 version of the Act states that "the couple is qualified to have a second child if one party of the spouses is disabled." This article was reversed in the December 2002 Act. In the 1987 Act, a remarried couple is qualified to have one child of their own only if one party has had no child and the other party has had no more than one child. The 2002 Act relaxed these rules a little: If one party is widowed before the current marriage, and the other party has had no child before, the spouses are qualified to have their own child even if the widowed party had two children in the previous marriage.
} 
[Figure VIII is here]

Following LPFP, the central government announced two more documents to strengthen enforcement of the ban on sex-selective abortions stated in LPFP: "The Prohibition of Ultrasound B Sex Screening and Induced Abortions" and "The Comprehensive Views on Curbing the Rising Sex Ratio," which were announced in January and June 2003, respectively. The two documents cannot cause the detected discontinuity because the announcements were even later than the period discussed above.

Another potentially relevant program is the "Care for Girls Program" (Guan Ai Nv Hai Xing Dong), which was initiated in 2003, aiming to mitigate discrimination against women and girls and eventually curb the rising sex ratio at birth. However, until February 2004, the program covered only 11 counties (among the 1,463 counties in China). Therefore, the nationwide decline in the sex ratio is not likely to be driven by this program.

\subsection{Supplementary Evidence on Women's Bargaining Power Improvement}

In this section, we show the improvement in women's bargaining power in such areas as household consumption. Our model suggests that women's private consumption could go either way following fewer sex-selective abortions. If the household decision switches from abortion to non-abortion, the wife's marginal utility of consumption is greater, which means that she is able to attain the same level of utility with less consumption. Thus, her consumption could be lower than it was before the improvement in divorce options. Therefore, we focus on households that are already done having children. For these households, fertility or sex-selective abortions are pre-determined, and improvement in the wife's utility within marriage can be unambiguously reflected by an increase in her consumption.

We use China's Health and Nutrition Survey (CHNS) data ${ }^{19}$ for this ana-

\footnotetext{
${ }^{19}$ CHNS was administered by the Population Center at the University of North Carolina in 1991, 1993, 1997, 2000, 2004, 2006, 2009 and 2011. The survey took place over a 3-day period using a multistage, random cluster process to draw a sample of about 4400 households with a total of 26,000 individuals in nine provinces. CHNS has detailed information on three-day
} 
lysis. Because the consumption and nutrition intake were measured during the survey in each three to four years, a rigrous $\mathrm{RD}$ exercise is not feasible. As a supplementary descriptive evidence, we examine the outcomes of household consumption by fitting the equation as follows:

$$
c_{i t}=\alpha+\operatorname{post}_{i t} \beta+\tau \cdot \theta+X_{i t} \gamma+\lambda+\varepsilon_{i t}
$$

where post $_{i t}$ is the dummy indicator of whether the sample is drawn from the wave after 2000. captures the linear trend of the calendar year. $X_{i t}$ is the vector of control variables similar to that in equation (1), $\tau$ is the linear time trend and $\lambda$ is the provincial fixed effect. We examine the outcome $c$ of husband's liquor and cigarettes consumption and children's calorie intake, respectively.

[Table VI is here]

The results are shown in Table VI. In Column (1), husbands' consumption of cigarettes decreases by 2.5 per day, which is significant at the one-percent level. In column (2), husbands' frequency of drinking alcohol also decreases at the ten-percent significance level. Column (3) shows that for each child, the three-day average calorie intake increases by 85.2 at the ten-percent significance level. These results are consistent with findings in the previous research: The improvement in women's bargaining power is associated with an increase in children's nutritional intake and, potentially, a decrease in men's liquor and cigarette consumption (Alderman and Haddad, 1997; Duflo, 2003; Pűetz and Webb, 1989; Thomas, 1990; Von Braun).

\section{Conclusions}

Using China's divorce law amendment for a regression discontinuity analysis of sex-selective abortions, we are able to elicit causal effects of control over household resources on household choices of public-good provision. Changes in the divorce laws are plausibly believed to be a pure shock to bargaining power for couples married before the reform. In order to probe the impact of average nutrition intake and consumption on liquor and cigarettes. 
bargaining power on gender inequality among children, using the divorce law reform rather than women's economic values gives us the advantage that the legislative innovation will not affect the economic return of having a daughter.

We find that households have had fewer sex-selective abortions since the enactment of this pro-women divorce law amendment, which rejects the unitary model of the household. An advantage of exploring this outcome is that it is more likely to reflect household decision making rather than differences in investment that are not meant to produce differential mortality, education attainment or nutrients.

We suggest the interpretation of divorce options as a relevant "threat" to household decision making. In addition, the asymmetric costs of providing household public goods are likely to provide an important channel through which bargaining power could affect household public-good provision.

An encouraging finding of this paper is that the empowerment of women within households substantially decreases the incidence of sex-selective abortions. This insight is valid even when women's preference for a son is as strong as their husbands', which is plausible in both China and India. Almond and Edlund (2008) depict a rather bleak picture of changing the preference toward sons among the second generation of Chinese US migrants. Our empirical analysis shows that the asymmetric costs upon sex-selective abortion make empowering women an efficient policy tool in curbing the rising sex ratio. In addition, improving women's bargaining power through legal innovation seems less costly and more efficient than banning ultrasound B sex screening. We also show that the effects of the divorce reform started to become evident shortly after implementation. The change is quite swift compared to economic growth, which gradually increases the return of having daughters through increasing women's economic value.

\section{References}

Aizer, Anna. "The gender wage gap and domestic violence." The American Economic Review (2010): 1847-1859. 
Almond, Douglas, and Lena Edlund. "Son-biased sex ratios in the 2000 United States Census." Proceedings of the National Academy of Sciences 105.15 (2008): 5681-5682.

Arnold, Fred, Minja Kim Choe, and T. K. Roy. "Son preference, the familybuilding process and child mortality in India." Population studies 52.3 (1998): 301-315.

Bates, Lisa M., Farzana Islam, Khairul Islam, and Sidney Ruth Schuler. 2004. "Legal Registration of Marriage in Bangladesh: An Intervention to Strengthen Women's Economic and Social Position and Protect Them against Domestic Violence?" Manuscript, Acad. Educ. Development, Washington, DC. Banerjee, Abhijit V. "Educational Policy and the Economics of the Family."Journal of Development Economics 74.1 (2004): 3-32.

Ben-Porath, Yoram. "The production of human capital and the life cycle of earnings." The Journal of Political Economy (1967): 352-365.

Ben-Porath, Voram. "Short-term fluctuations in fertility and economic activity in Israel." Demography 10.2 (1973): 185-204.

Ben-Porath, Yoram, and Finis Welch. "Do sex preferences really matter?." The Quarterly Journal of Economics 90.2 (1976): 285-307.

Blundell, Richard, Pierre-André Chiappori, and Costas Meghir. "Collective labor supply with children." Journal of Political Economy 113.6 (2005): 12771306.

Browning, Martin, and Pierre-Andre Chiappori. "Efficient intra-household allocations: A general characterization and empirical tests." Econometrica (1998): 1241-1278.

Burgess, Robin, and Juzhong Zhuang. "Modernisation and son preference." (2000). 
Calonico, Sebastian, Matias D. Cattaneo, and Rocio Titiunik. "Robust nonparametric confidence intervals for regression-discontinuity designs." Revision requested by Econometrica (2013).

Chay, Kenneth Y., Patrick J. McEwan, and Miguel Urquiola. "The Central Role of Noise in Evaluating Interventions That Use Test Scores to Rank Schools." American Economic Review 95.4 (2005): 1237-1258.

Chiappori, Pierre-André, Murat Iyigun, and Yoram Weiss. Public goods, transferable utility and divorce laws. No. 2646. IZA Discussion Papers, 2007.

Chiappori, Pierre-André, Yoram Weiss, "Divorce, Remarriage and Welfare: A General Equilibrium Approach " Journal of the European Economic Association, 4(2-3), 2006, pp.415-426.

Chu, Junhong. "Prenatal sex determination and sex-selective abortion in rural central China." Population and Development Review 27.2 (2001): 259-281.

Clark, Shelley. "Son preference and sex composition of children: Evidence from India." Demography 37.1 (2000): 95-108.

Gupta, Monica Das. "Selective discrimination against female children in rural Punjab, India." Population and development review (1987): 77-100.

Duflo, Esther. "Grandmothers and Granddaughters: Old Age Pensions and Intrahousehold Allocation in South Africa." (2003).

Duflo, Esther. "Women Empowerment and Economic Development." Journal of Economic Literature 50.4 (2012): 1051-79.

Ebenstein, Avraham. "The "missing girls" of China and the unintended consequences of the one child policy." Journal of Human Resources 45.1 (2010): $87-115$.

Field, Erica, and Attila Ambrus. "Early marriage, age of menarche, and female schooling attainment in Bangladesh." Journal of Political Economy 116.5 (2008): 881-930. 
Foster, Andrew, and Mark Rosenzweig. "Missing women, the marriage market and economic growth." Unpublished manuscript available at http://adfdell. pstc. brown. edu/papers/sex. pdf (2001).

Gray, Jeffrey S. "Divorce-Law Changes, Household Bargaining, and Married Women's Labor Supply." American Economic Review 88.3 (1998): 628-42.

Goodkind, Daniel. "Child underreporting, fertility, and sex ratio imbalance in China." Demography 48.1 (2011): 291-316.

Gruber, Jonathan, "Is making divorce easier bad for children? The long-run implications of unilateral divorce," Journal of Labor Economics Vol.22, No.4 (October 2004), pp. 799-833.

Haddad, Lawrence, John Hoddinott, and Harold Alderman. Intrahousehold resource allocation in developing countries: models, methods, and policy. Johns Hopkins University Press, 1997.

Imbens, Guido W., and Thomas Lemieux. "Regression discontinuity designs: A guide to practice." Journal of Econometrics 142.2 (2008): 615-635.

Imbens G, Kalyanaraman K. Optimal Bandwidth Choice for the Regression Discontinuity Estimator. Review of Economic Studies (2012) 79 (3): 933-959.

Lafortune, Jeanne, et al. "Changing the Rules Midway: The Impact of Granting Alimony Rights on Existing and Newly-Formed Partnerships." Unpublished manuscript (2012).

Li, Shuzhuo, Yan Wei, and Marcus W. Feldman. "Son Preference and Induced Abortion in Rural China: Findings from the 2001 National Family Planning and Reproductive Health Survey." (2005).

Li, Shuzhuo. "Imbalanced sex ratio at birth and comprehensive intervention in China." (2007).

Li, Hongbin, and Hui Zheng. "Ultrasonography and sex ratios in China." Asian Economic Policy Review 4.1 (2009): 121-137. 
Cecilia Chan, Liu Meng. "Family violence in China: Past and present." Journal of Comparative Social Welfare 16.1 (2000): 74-87.

Manser, Marilyn, and Murray Brown. "Marriage and household decisionmaking: A bargaining analysis." International economic review (1980): 31-44.

McCrary, Justin. "Manipulation of the running variable in the regression discontinuity design: A density test." Journal of Econometrics 142.2 (2008): 698714.[34] Manser, Marilyn, Murray Brown, "Marriage and household decisionmaking: A bargaining analysis," International Economic Review, 21(1), 1980.

McElroy, Marjorie B., and Mary Jean Horney. "Nash-bargained household decisions: Toward a generalization of the theory of demand." International Economic Review 22.2 (1981): 333-349.

McElroy, Marjorie B. "The Empirical Content of Nash-Bargained Household Behavior." Journal of human resources 25.4 (1990).

Pörtner, Claus C. "Sex selective abortions, fertility and birth spacing." University of Washington, Department of Economics, Working Paper (2010).

Rangel, Marcos A. "Alimony rights and intrahousehold allocation of resources: Evidence from brazil." The Economic Journal 116.513 (2006): 627-658.

Rohlfs, Chris, Alexander Reed, and Hiroyuki Yamada. "Causal effects of sex preference on sex-blind and sex-selective child avoidance and substitution across birth years: Evidence from the Japanese year of the fire horse." Journal of Development Economics 92.1 (2010): 82-95.

Rosenzweig, Mark R., and T. Paul Schultz. "Market opportunities, genetic endowments, and intrafamily resource distribution: Child survival in rural India." The American Economic Review (1982): 803-815.

Sturm, Roland, and Junsen Zhang. "Fecundibility and social development in China: changes in the distribution of the first conception interval." Biometrical journal 35.8 (1993): 985-995. 
Qian, Nancy. "Missing women and the price of tea in China: The effect of sex-specific earnings on sex imbalance." The Quarterly Journal of Economics 123.3 (2008): 1251-1285.

Scharping, Thomas. Birth Control in China 1949-2000: Population policy and demographic development. Routledge, 2003.

Sen, Amartya. "More than 100 million women are missing." The New York Review of Books 37 (1990).

Sen, Amartya. "Missing women." BMJ: British Medical Journal 304.6827 (1992): 587.

Stevenson, Betsey. "Divorce law and women's labor supply." Journal of Empirical Legal Studies 5.4 (2008): 853-873.

Stevenson, Betsey, and Justin Wolfers. "Bargaining in the shadow of the law: Divorce laws and family distress." The Quarterly Journal of Economics 121.1 (2006): 267-288.

Thomas, Duncan. "Intra-Household Resource Allocation An Inferential Approach." Journal of human resources 25.4 (1990).

Thomas, Duncan, John Strauss, and Maria-Helena Henriques. "How does mother's education affect child height?." Journal of human resources (1991): 183-211.

Von Braun, Joachim, Detlev Puetz, and Patrick Webb. Irrigation technology and commercialization of rice in The Gambia, effects on income and nutrition. No. 75. Intl Food Policy Res Inst, 1989.

Yi, Zeng, et al. "Causes and implications of the recent increase in the reported sex ratio at birth in China." Population and Development Review (1993): 283-302.

Zeng, Yi, Deqing Wu, "Regional Analysis of Divorce in China since 1980," Demography Vol. 37, No. 2 (May, 2000), pp.215-219. 
Figure I.

Household Utility Pareto Frontier and Comparative Statics

Figure I.A. Household Utility Pareto Frontiers When $e_{A}$ is Large Enough Relative to $e_{N A}$

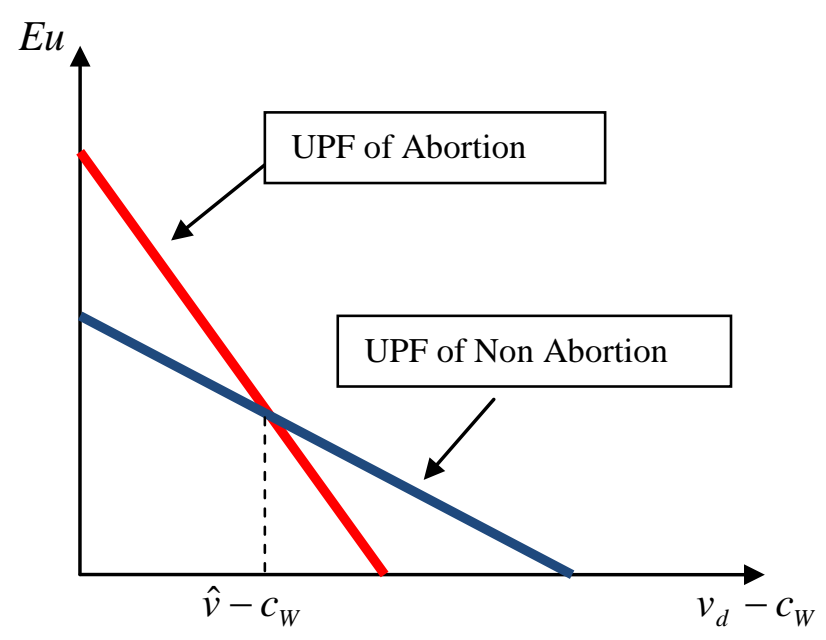

Note: Figure I.A shows the utility Pareto frontier (UPF) upon abortion and non-abortion. The UPF of abortion has a higher slope because the wife's marginal utility of private consumption decreases upon abortion, while the husband's remains intact. The MRS of private consumption between the husband and wife gets larger. The two UPFs intersects at $\hat{v}-c_{W}$. Households with $v_{d}<\hat{v}$ choose to have an abortion, while households with $v_{d}>\hat{v}$ choose non-abortion.

Figure I.B. Household Utility Pareto Frontiers When $e_{A}$ is Not Large Enough Relative to $e_{N A}$

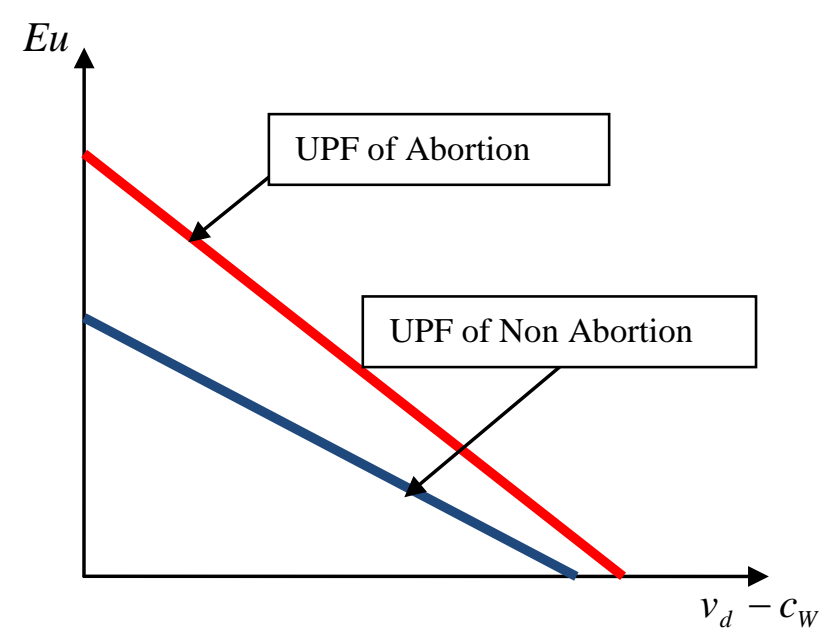

Note: Figure I.B shows the case in which the abortion costs are negligible. The UPF of abortion lies outside of that of non-abortion for all values of $v_{d}$. All households choose to have an abortion. 
Figure II.

Sex ratio of the Second-born Children after Having Firstborn Daughters

Figure II.A. Sample Mean of Sex Ratio by Cohort

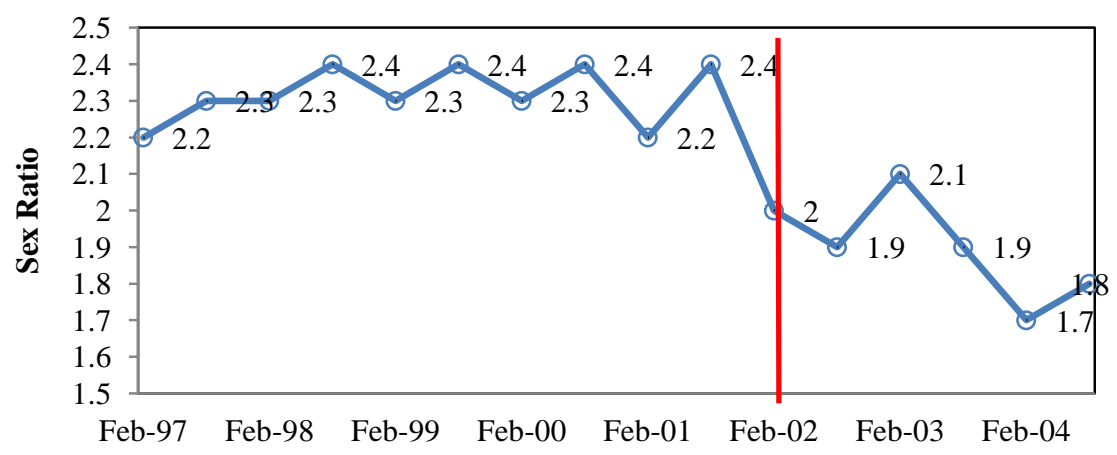

Cohort by Conception Month

Figure II.B. Coefficient and 95\% C.I. of the Cohort indicators

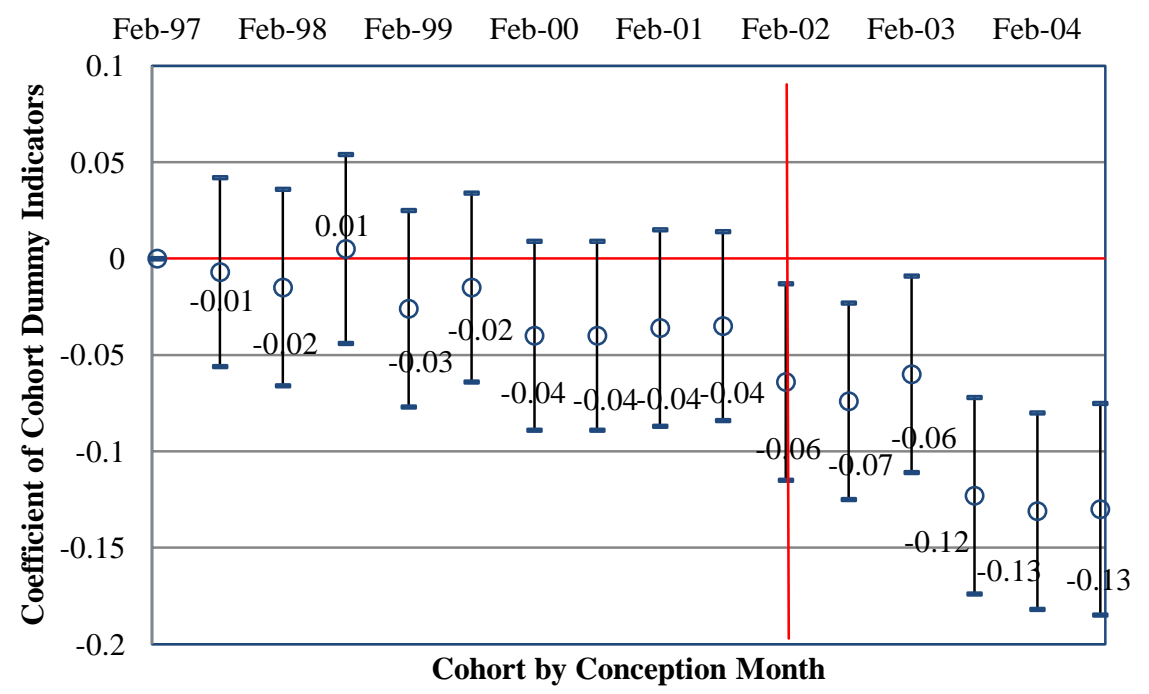

Source: The 25-percent sample of the 2005 One-Percent Population Survey.

Note: The sample is confined to the second child of rural households with a firstborn daughter, born between 1997 and 2005 (the four years around the implementation), and the parents married before the divorce law amendment. The children are categorized by the timing of their conception. Each cohort is defined as all babies conceived in each six-month period following February 1997. In Figure II.A, the sex ratio is the ratio of the number of boys to the number of girls. In Figure IIB, the circles are the coefficients of the cohort indicators, and the lines are the 95percent confidence interval of the regression Male $_{i c}=\alpha+\sum_{l=1}^{15} 1[c=l] \beta_{l}+X_{i p c} \gamma+\lambda+\varepsilon_{i p c}$. Each dummy variable indicates a six-month period during which the second child was conceived. The control variables include provincial fixed effects and parents' characteristics described in Table I. 
Figure III.

The Timing Threshold when the Divorce Reform Started to Affect Sex-Selective Abortions

Figure IIIA. Adjusted R-squared from OLS regressions for sequence of thresholds

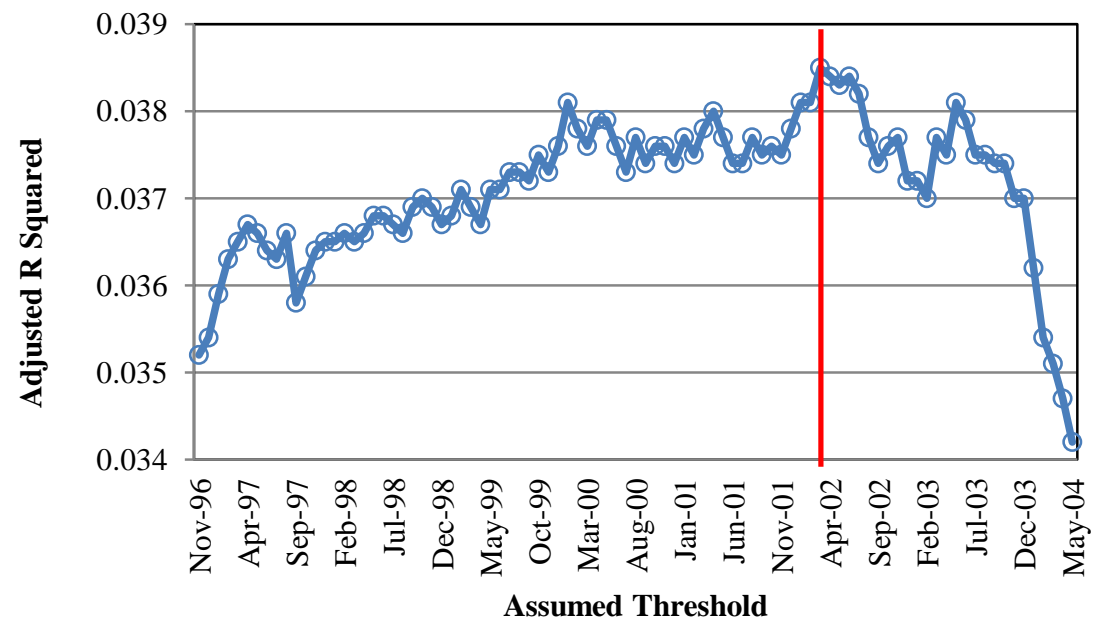

Figure IIIB. Magnitude of T-ratios from OLS regressions for sequence of thresholds

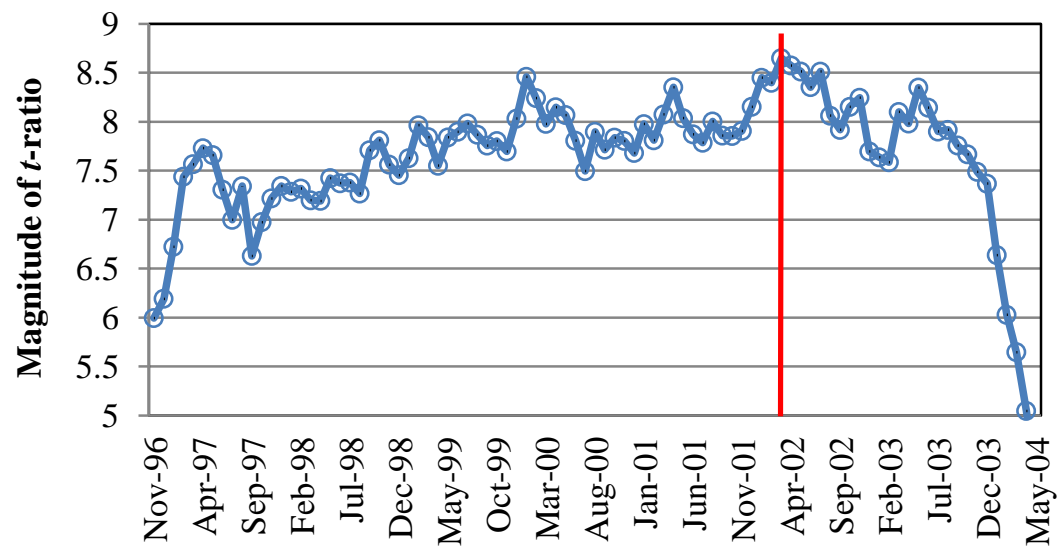

Assumed Threshold

Source: The 25-percent sample of the 2005 One-Percent Population Survey.

Note: The sample is confined to the second birth of rural households with a firstborn daughter and the husband and wife married before the divorce law amendment. Figure III.A plots the adjusted $R$-squared, and Figure III.B plots the magnitude of $t$-ratios of $\beta_{l}$ in a series of regressions Male $_{i c}=\alpha+1[c \geq l] \beta_{l}+X_{i c} \gamma+\lambda+\varepsilon_{i c}$, where $l$ is the timing of the mother's conception (precise to month) marked in the horizontal axis. 
Figure IV.

The Relationship between Timing of Mother's Conception and Propensity to Have a Second-born Son after a Firstborn Daughter

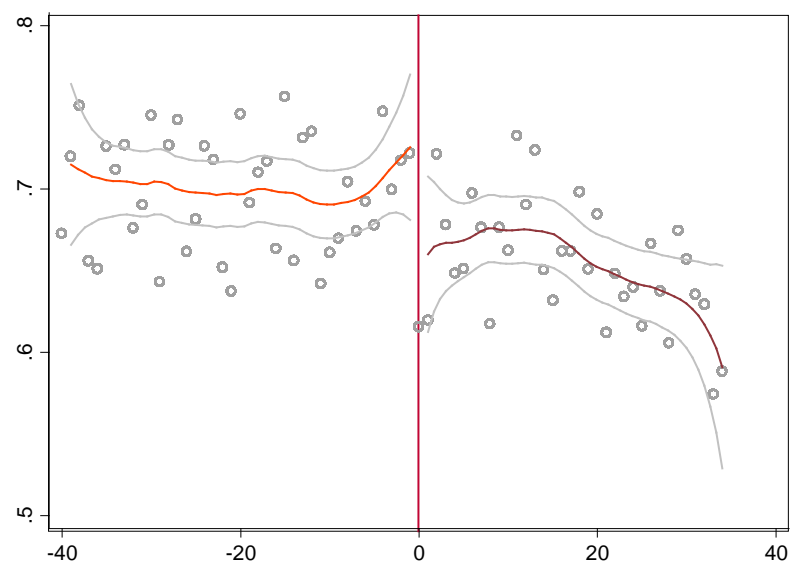

Source: The 25-percent sample of the 2005 One-Percent Population Survey.

Note: The sample is confined to the second birth of rural households with a firstborn daughter and the husband and wife married before the divorce law amendment. This figure shows the relationship between timing of the mother's conception and the sex of the child. The circles are the average of the dummy indicator of the second child being a son ( 1 if the second child is a son, 0 otherwise) for groups of children defined by the conception months relative to the threshold February 2002. The curves represent the smoothed values from a kernel-weighted second-degree local polynomial regression of the dummy indicator of the second child being a son on the relative month to the threshold (February 2002) at the left and right side of the cutoff, respectively. The thin, grey-colored curves show the 95percent confidence band. 


\section{Figure V.}

The Relationship between Timing of Mother's Conception and the Spacing between a Firstborn Daughter and a Second-Born Child

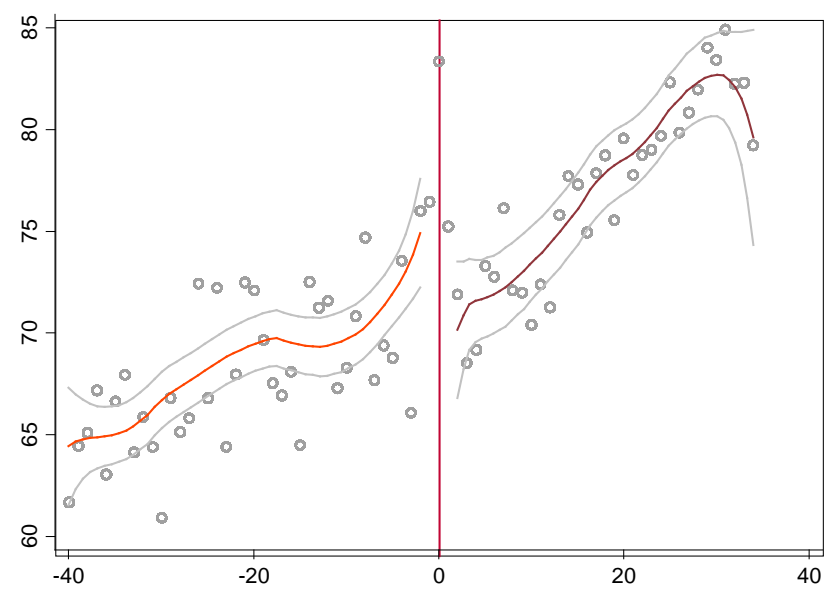

Source: The 25-percent sample of the 2005 One-Percent Population Survey.

Note: The sample is confined to the second birth of rural households with a firstborn daughter and the husband and wife married before the divorce law amendment. This figure shows the relationship between the timing of the mother's conception and the birth spacing between a firstborn daughter and a second-born child. The circles are the average of birth spacing for groups of children defined by the conception months relative to the threshold February 2002. The curves represent the smoothed values from a kernel-weighted second-degree local polynomial regression of birth spacing on relative month to the threshold (February 2002) at the left and right side of the cutoff, respectively. The thin, grey-colored curves show the 95-percent confidence band. 
Figure VI. Testing Continuity of the Density of Conception Month

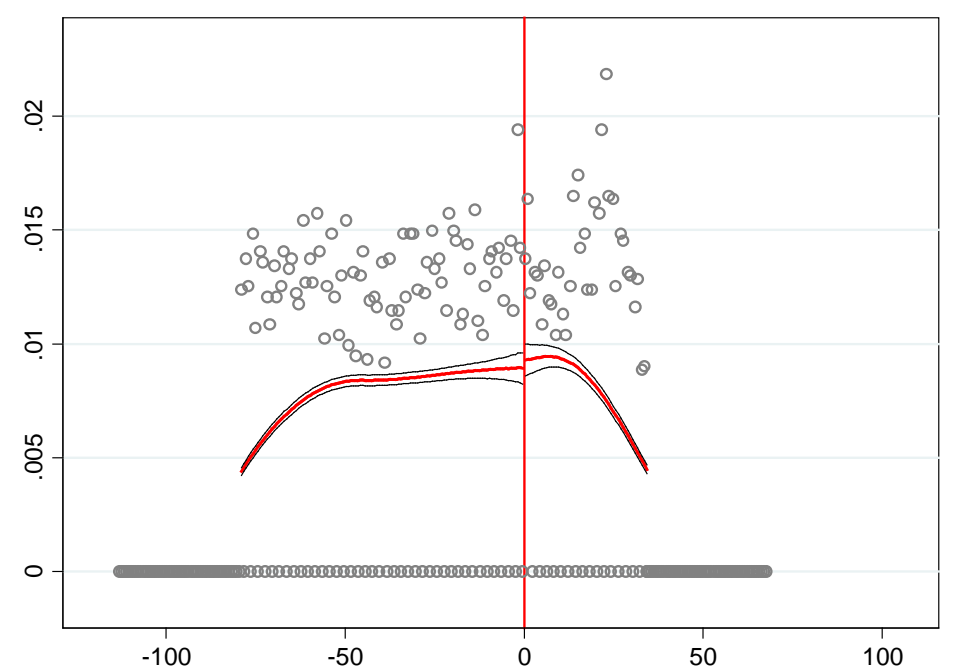

Note: The estimated density of the relative conception month is presented for all children conceived between February 1997 and May 2004.The figure results from the implementation of McCrary's (2008) density test, which does not reject the null of continuity at 0 ( $\mathrm{t}$-stat $=0.696)$. The red curve is the smoothed value from the kernel weighted local linear regressions to smooth a finely-gridded histogram, and the grey lines are the $95 \%$ confidence band. 
Figure VII.

Testing the Discontinuity of Pre-determined Household Characteristics

Figure VIIA. Mother's Schooling Years

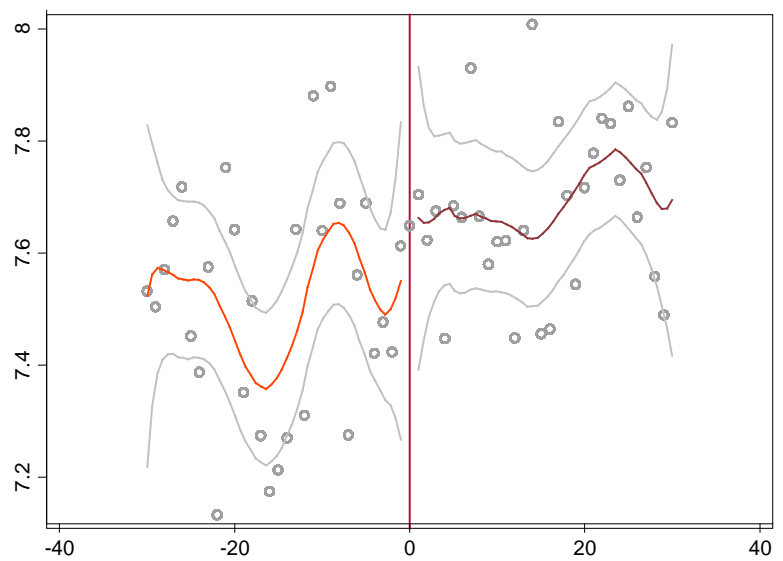

Figure VIIC. Mother's Age at First Marriage

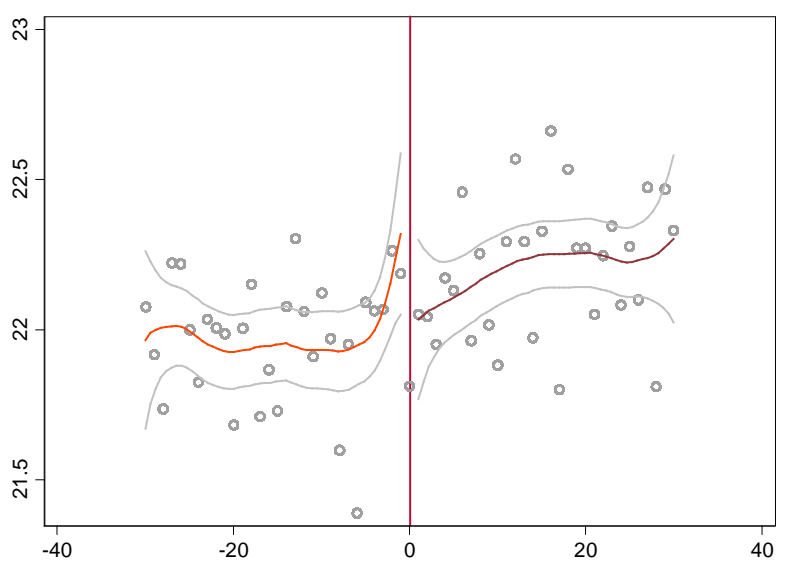

Figure VIIB. Father's Schooling Years

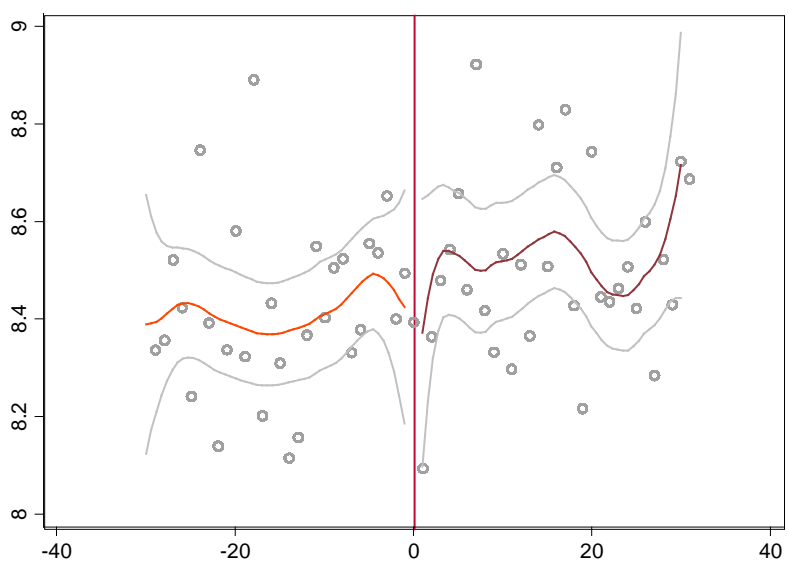

Figure VIID. Father's Age at First Marriage

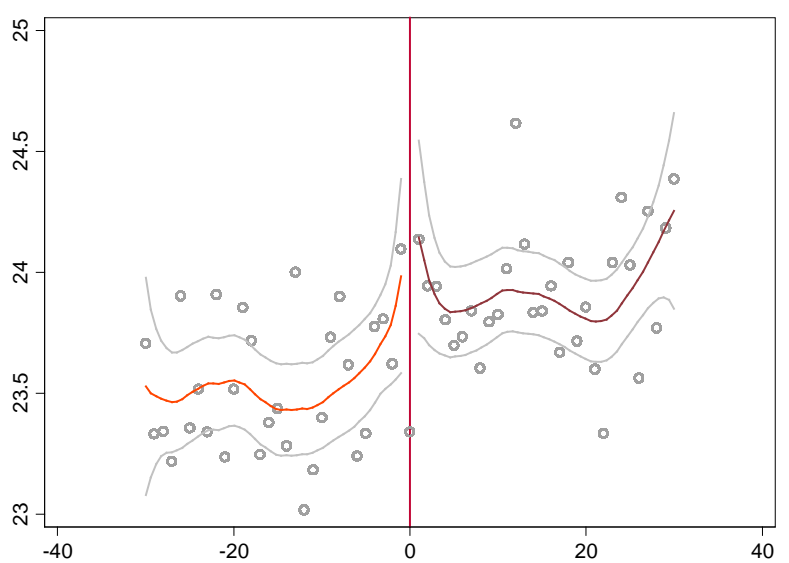

Source: The 25-percent sample of the 2005 One-Percent Population Survey.

Note: The sample is confined to the second birth of rural households with a firstborn daughter and the husband and wife married before the divorce law amendment. This figure shows the relationship between the timing of conception and pre-determined characteristics of the mother and father. The top panel shows the relationship between the timing of conception and parents' schooling years. The bottom panel shows the relationship between the timing of conception and parents' age at first marriage.

The circles are the average of parental characteristics for groups of children defined by the conception months relative to the threshold February 2002. The curves represent the smoothed values from a kernel-weighted seconddegree local polynomial regression of parental characteristics on the relative month to the threshold at the left and right side of the cutoff, respectively. The thin, grey-colored curves show the 95-percent confidence band. 


\section{Figure VIII.}

The Relationship between the Relative Time of Mother's Conception to Implementation of Local FamilyPlanning Policy and Propensity to Have a Son after a Firstborn Daughter

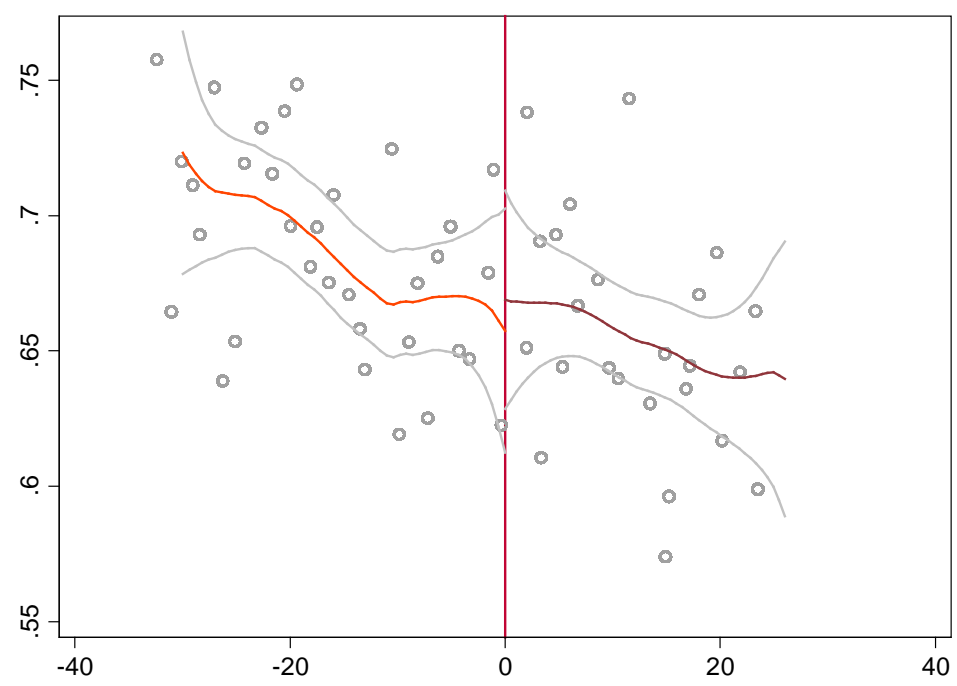

Source: The 25-percent sample of the 2005 One-Percent Population Survey.

Note: The sample is confined to the second birth of rural households with a firstborn daughter and the husband and wife married before the divorce law amendment. This figure shows the relationship between the relative time of the mother's conception and the implementation of local family-planning policy and the sex of child.

The circles are the sample mean of the dummy indicator of the second child being a son (1 if the second child is a son, 0 otherwise) in each month relative to the timing of implementation in the particular locality. The curves represent the smoothed values from a kernel-weighted second-degree local polynomial regression of the dummy indicator of the second child being a son on relative month to the timing of implementation in the locality at the left and right side of the cutoff, respectively. The thin, grey-colored curves show the 95-percent confidence band. 


\section{Table I.}

\section{Descriptive Statistics}

\begin{tabular}{lcc}
\hline \hline & Mean & Standard deviation \\
\hline Ratio of male births after a firstborn girl & 0.665 & 0.472 \\
Mother's schooling years & 7.344 & 2.585 \\
Father's schooling years & 8.239 & 2.154 \\
Mother's workforce participation & 0.636 & 0.753 \\
Father's workforce participation & 0.934 & 0.324 \\
Mother being a migrant & 0.086 & 0.281 \\
Father being a migrant & 0.072 & 0.258 \\
Mother's age at first marriage & 22.116 & 2.750 \\
Father's age at first marriage & 23.764 & 2.330 \\
\hline \hline
\end{tabular}

Note: The results use the sample of the 2005 One-percent Population Survey. The sample is confined to the second birth of rural households with a firstborn daughter, born between 1997 and 2005 (four years around the implementation), and the husband and wife married before the divorce law amendment. 
Table II.

The Effect of Divorce Law Amendment on Children's Sex Ratio

Reduced-Form RD Estimates using non-parametric method of Local Linear Regression and OLS regressions with control functions

\begin{tabular}{|c|c|c|c|c|c|c|}
\hline & \multicolumn{3}{|c|}{ "Local Linear Regression } & \multicolumn{3}{|c|}{ OLS with Control functions } \\
\hline & (1) & (2) & (3) & (4) & (5) & (6) \\
\hline RD estimand & $\begin{array}{c}-0.089 * * * \\
(0.031)\end{array}$ & $\begin{array}{c}-0.035^{* * *} \\
(0.012)\end{array}$ & $\begin{array}{c}-0.027^{* * *} \\
(0.010)\end{array}$ & $\begin{array}{c}-0.041 * * \\
(0.019)\end{array}$ & $\begin{array}{c}-0.055^{* *} \\
(0.026)\end{array}$ & $\begin{array}{c}-0.080 * * \\
(0.031)\end{array}$ \\
\hline BW Туре & CCT & IK & $\mathrm{CV}$ & & & \\
\hline Bandwidth & 9.518 & 27.698 & 34 & & & \\
\hline Kernel Type & Triangular & Triangular & Triangular & & & \\
\hline $\begin{array}{l}\text { Control } \\
\text { Functions }\end{array}$ & & & & $\begin{array}{l}\text { 2nd-order } \\
\text { polynomial }\end{array}$ & $\begin{array}{c}\text { 3rd-order } \\
\text { polynomial }\end{array}$ & $\begin{array}{c}\text { 4th-order } \\
\text { polynomial }\end{array}$ \\
\hline Observations & 3,686 & 10,964 & 13,090 & 21,582 & 21,582 & 21,582 \\
\hline
\end{tabular}

Note: The results use the sample of the 2005 One-percent Population Survey. The sample is confined to the second birth of rural households with a firstborn daughter, born between 1997 and 2005 (four years around the implementation), and the husband and wife married before the divorce law amendment. In Columns (1)-(3), we use local linear regression and triangular kernel and choose the bandwidth by the method proposed by Calonico, Cattaneo and Titiunik (2013a), Imbens and Kalyanaraman (2012), and Imbens and Lemieus (2007), respectively. Columns (4)-(6) report the OLS estimand with second-, third- and fourth-order polynomial control functions of the running variable, respectively.

The numbers in parentheses are robust standard errors.

*** significant at the one-percent level. ${ }^{* *}$ significant at the five-percent level. *significant at the ten-percent level. 
Table III.

The Effect of Divorce Law Amendment on Birth Spacing Reduced-Form RD Estimates using non-parametric method of Local Linear Regression and OLS regressions with control functions

\begin{tabular}{|c|c|c|c|c|c|c|}
\hline & \multicolumn{3}{|c|}{ "Local Linear Regression } & \multicolumn{3}{|c|}{ OLS with Control functions } \\
\hline & (1) & (2) & (3) & (4) & (5) & (6) \\
\hline RD estimand & $\begin{array}{l}-3.386^{*} \\
(2.129)\end{array}$ & $\begin{array}{c}-2.669 * * \\
(1.151)\end{array}$ & $\begin{array}{c}-2.589 * * \\
(1.277)\end{array}$ & $\begin{array}{l}-2.303^{*} \\
(1.543)\end{array}$ & $\begin{array}{c}-0.404 \\
(2.124)\end{array}$ & $\begin{array}{l}-0.617 \\
(2.804)\end{array}$ \\
\hline BW Туре & CCT & IK & $\mathrm{CV}$ & & & \\
\hline Bandwidth & 11.970 & 43.781 & 33 & & & \\
\hline Kernel Type & Triangular & Triangular & Triangular & & & \\
\hline $\begin{array}{l}\text { Control } \\
\text { Functions }\end{array}$ & & & & $\begin{array}{l}\text { 2nd-order } \\
\text { polynomial }\end{array}$ & $\begin{array}{c}\text { 3rd-order } \\
\text { polynomial }\end{array}$ & $\begin{array}{c}\text { 4th-order } \\
\text { polynomial }\end{array}$ \\
\hline Observations & 4,291 & 14,885 & 12,596 & 21,408 & 21,408 & 21,408 \\
\hline
\end{tabular}

Note: The results use the sample of the 2005 One-percent Population Survey. The sample is confined to the second birth of rural households with a firstborn daughter, born between 1997 and 2005 (four years around the implementation), and the husband and wife married before the divorce law amendment. In Columns (1)-(3), we use local linear regression and triangular kernel and choose the bandwidth by the method proposed by Calonico, Cattaneo and Titiunik (2013a), Imbens and Kalyanaraman (2012), and Imbens and Lemieus (2007), respectively. Columns (4)-(6) report the OLS estimand with second-, third- and fourth-order polynomial control functions of the running variable, respectively.

The numbers in parentheses are robust standard errors.

*** significant at the one-percent level. **significant at the five-percent level. *significant at the ten-percent level. 
Table IV.

Heterogeneity of the Change in Children's Sex across Women with Different Health-related Costs

\begin{tabular}{|c|c|c|c|c|c|}
\hline \multirow[t]{2}{*}{ VARIABLE } & & \multicolumn{4}{|c|}{ Indicator of having a second-born son } \\
\hline & & (1) & (2) & (3) & (4) \\
\hline \multirow{14}{*}{$\begin{array}{l}\text { Estimated differences in the } \\
\text { change by relative years } \\
\text { among women with different } \\
\text { intervals between marriage } \\
\text { and having first child }\end{array}$} & -1 & $\begin{array}{l}-0.013 \\
(0.010)\end{array}$ & $\begin{array}{l}-0.013 \\
(0.009)\end{array}$ & $\begin{array}{l}-0.012 \\
(0.009)\end{array}$ & $\begin{array}{l}-0.006 \\
(0.010)\end{array}$ \\
\hline & & -0.014 & -0.014 & -0.013 & -0.010 \\
\hline & -0.5 & $(0.009)$ & $(0.009)$ & $(0.008)$ & $(0.010)$ \\
\hline & 0.5 & $\begin{array}{c}-0.008 \\
(0.009)\end{array}$ & $\begin{array}{l}-0.008 \\
(0.009)\end{array}$ & $\begin{array}{c}-0.009 \\
(0.009)\end{array}$ & $\begin{array}{c}-0.008 \\
(0.010)\end{array}$ \\
\hline & & $-0.026^{* * *}$ & $-0.025 * * *$ & $-0.024 * * *$ & $-0.026 * * *$ \\
\hline & 1 & $(0.010)$ & $(0.009)$ & $(0.009)$ & $(0.010)$ \\
\hline & & $-0.017 *$ & $-0.016^{*}$ & $-0.017 * *$ & $-0.018 * *$ \\
\hline & 1.5 & $(0.009)$ & $(0.009)$ & $(0.008)$ & $(0.009)$ \\
\hline & $?$ & -0.007 & -0.007 & -0.007 & -0.006 \\
\hline & 2 & $(0.010)$ & $(0.009)$ & $(0.009)$ & $(0.010)$ \\
\hline & 25 & $-0.017 *$ & $-0.017 *$ & $-0.015 *$ & $-0.015^{*}$ \\
\hline & 2.3 & $(0.009)$ & $(0.009)$ & $(0.008)$ & $(0.010)$ \\
\hline & 3 & -0.010 & -0.010 & -0.009 & -0.008 \\
\hline & & $(0.010)$ & $(0.009)$ & $(0.009)$ & $(0.011)$ \\
\hline Province and cohort f.e. & & Yes & Yes & Yes & Yes \\
\hline Parental Characteristics & & & Yes & Yes & Yes \\
\hline If parents are migrants & & & & Yes & Yes \\
\hline $\begin{array}{l}\text { Exclude women having } 1 \text { st } \\
\text { child }>4 \text { yrs after marriage }\end{array}$ & & & & & Yes \\
\hline Adjusted R squared & & 0.039 & 0.039 & 0.038 & 0.042 \\
\hline Observations & & 10,487 & 10,487 & 10,487 & 10,099 \\
\hline
\end{tabular}

Note: The results use the sample of the 2005 One-percent Population Survey. The sample is confined to the second birth of rural households with a firstborn daughter, born between 1997 and 2005 (four years around the implementation), and the husband and wife married before the divorce law amendment. The dependent variable is the dummy indicator of having a second-born son. The entries in this table are coefficients of a dummy variable for being conceived within a certain half-year period interacted with the mother's time interval between marriage and having her first child. The numbers in parentheses are the robust standard errors. The cohort conceived during the period between February and July 1997 is the reference group.

*** significant at the one-percent level. **significant at the five-percent level. *significant at the ten-percent level. 
Table V.

Heterogeneity of the Change in Birth Spacing across Women with Different Health-related Costs

\begin{tabular}{|c|c|c|c|c|c|}
\hline \multirow[t]{2}{*}{ VARIABLE } & & \multicolumn{4}{|c|}{ Birth Spacing (months) } \\
\hline & & (1) & (2) & (3) & (4) \\
\hline \multirow{16}{*}{$\begin{array}{l}\text { Estimated differences in the } \\
\text { change by relative years } \\
\text { among women with different } \\
\text { intervals between marriage } \\
\text { and having first child }\end{array}$} & & $-0.410^{*}$ & -0.308 & -0.329 & -0.229 \\
\hline & -1 & $(0.233)$ & $(0.234)$ & $(0.208)$ & $(0.163)$ \\
\hline & & -0.342 & -0.328 & -0.292 & -0.294 \\
\hline & -0.5 & $(0.241)$ & $(0.241)$ & $(0.218)$ & $(0.187)$ \\
\hline & & -0.330 & -0.330 & -0.129 & -0.032 \\
\hline & 0.5 & $(0.229)$ & $(0.229)$ & $(0.204)$ & $(0.160)$ \\
\hline & & $-0.388 *$ & $-0.389 *$ & -0.238 & -0.023 \\
\hline & 1 & $(0.231)$ & $(0.231)$ & $(0.201)$ & $(0.154)$ \\
\hline & & -0.338 & -0.337 & $-0.433 * *$ & -0.211 \\
\hline & 1.5 & $(0.230)$ & $(0.230)$ & $(0.199)$ & $(0.152)$ \\
\hline & & $-0.484 * *$ & $-0.486 * *$ & $-0.635^{* * *}$ & $-0.513 * * *$ \\
\hline & 2 & $(0.234)$ & $(0.234)$ & $(0.231)$ & $(0.212)$ \\
\hline & 25 & -0.390 & -0.393 & -0.301 & -0.108 \\
\hline & 2.0 & $(0.261)$ & $(0.261)$ & $(0.209)$ & $(0.173)$ \\
\hline & & -0.375 & -0.373 & $-0.387^{*}$ & -0.104 \\
\hline & 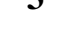 & $(0.248)$ & $(0.248)$ & $(0.221)$ & $(0.169)$ \\
\hline Province and cohort f.e. & & Yes & Yes & Yes & Yes \\
\hline Parental Characteristics & & & Yes & Yes & Yes \\
\hline If parents are migrants & & & & Yes & Yes \\
\hline $\begin{array}{l}\text { Exclude women having } 1 \text { st } \\
\text { child }>4 \text { yrs after marriage }\end{array}$ & & & & & Yes \\
\hline Adjusted R squared & & 0.496 & 0.486 & 0.502 & 0.494 \\
\hline Observations & & 10,487 & 10,487 & 10,487 & 10,099 \\
\hline
\end{tabular}

Note: The results use the sample of the 2005 One-percent Population Survey. The sample is confined to the second birth of rural households with a firstborn daughter, born between 1997 and 2005 (four years around the implementation), and the husband and wife married before the divorce law amendment. The dependent variable is the spacing between the first and second children in a household. The entries in this table are coefficients of a dummy variable for being conceived within a certain half-year period interacted with the mother's time interval between marriage and having her first child. The numbers in parentheses are the robust standard errors. The cohort conceived during the period between February and July 1997 is the reference group.

*** significant at the one-percent level. **significant at the five-percent level. *significant at the ten-percent level. 
Table VI.

Consumption in Households That Were Done Having Children Before 2001

\begin{tabular}{lcccc}
\hline \hline \multirow{2}{*}{ VARIABLE } & \multicolumn{2}{c}{$\begin{array}{c}\text { Husband's Liquor and Cigarettes Consumption } \\
\text { \#cigarettes per day }\end{array}$} & & $\begin{array}{c}\text { Each Child's Caloric intake } \\
\text { (3-day average) }\end{array}$ \\
\cline { 2 - 3 } Post & $\mathbf{( 1 )}$ & $\mathbf{( 2 )}$ & $-0.205^{*}$ & $\mathbf{( 3 )}$ \\
& $-2.505^{* * *}$ & $(0.116)$ & & $85.221^{*}$ \\
Controls & $(0.639)$ & Yes & & $(47.980)$ \\
Community f.e. & Yes & Yes & Yes \\
Time trend & Yes & Yes & Yes \\
Adjusted R squared & 0.165 & 0.101 & Yes \\
Observations & 3,479 & 5,197 & 0.344 \\
\hline \hline
\end{tabular}

Source: The 1993, 1997, 2000, 2004, 2006 and 2009 waves of the longitudinal data of the China Health and Nutrition Survey (CHNS).

Note: The results use the sample composed of the 1993, 1997, 2000, 2004, 2006 and 2009 waves of the longitudinal data of the China Health and Nutrition Survey (CHNS). The sample is confined to rural women who finished having children according to the family-planning policy (households that had one son, one son and one daughter or two daughters by 2001). The dependent variables in columns (1) -(3) are the husband's daily consumption of cigarettes, the husband's frequency of taking alcohol and the three-day average of each child's caloric intake, respectively. The frequency of having alcohol=0 if the husband had no alcohol in last year; $=1$ if less than once a month; $=2$ if one to three times per months; $=3$ if one to two times per week; $=4$ if three to four times per week; $=5$ if the husband drinks every day. The entries report the coefficient of the dummy indicator of whether the observation is from a wave post 2001. (post $=1$ if an observation is from a wave later than 2001; post $=0$ otherwise). The numbers in parentheses are the robust standard errors. The control variables include spouses' demographic and social economic characteristics.

*** significant at the one-percent level. **significant at the five-percent level. *significant at the ten-percent level. 


\section{Appendix Figures and Tables}

Table AI

The Timing Variations in Law of Population and Family Planning Implementation across Provinces

\begin{tabular}{lcc|lcc}
\hline Province & $\begin{array}{c}\text { Time of } \\
\text { Provincial Act } \\
\text { Being Passed }\end{array}$ & $\begin{array}{c}\text { Time of } \\
\text { Provincial Act } \\
\text { Being Enacted }\end{array}$ & Province & $\begin{array}{c}\text { Time of Provincial } \\
\text { Act } \\
\text { Being Passed }\end{array}$ & $\begin{array}{c}\text { Time of Provincial } \\
\text { Act } \\
\text { Being Enacted }\end{array}$ \\
\hline Beijing & 18-Jul-03 & 1-Sep-03 & Henan & 30-Nov-02 & 1-Jan-03 \\
Tianjin & 11-Jul-03 & 1-Sep-03 & Hubei & 1-Dec-02 & 1-Jan-03 \\
Hebei & 25-Mar-03 & 1-Oct-03 & Hunan & 29-Nov-02 & 1-Jan-03 \\
Shanxi & 28-Sep-02 & 1-Nov-02 & Guangdong & 25-Jul-02 & 1-Sep-02 \\
Inner Mongolia & 25-Sep-02 & 1-Nov-02 & Guangxi & 27-Jul-02 & 1-Sep-02 \\
Liaoning & 16-Jan-03 & 1-Apr-03 & Hainan & 24-Oct-03 & 1-Dec-03 \\
Jilin & 27-Sep-02 & 1-Nov-02 & Chongqing & 25-Sep-02 & 1-Nov-02 \\
Heilongjiang & 18-Oct-02 & 1-Jan-03 & Sichuan & 26-Sep-02 & 1-Oct-02 \\
Shanghai & 31-Dec-03 & 15-Apr-04 & Guizhou & 29-Sep-02 & 29-Sep-02 \\
Jiangsu & 23-Oct-02 & 1-Dec-02 & Yunnan & 25-Jul-02 & 1-Sep-02 \\
Zhejiang & 3-Sep-02 & 3-Sep-02 & Shaanxi & 29-Sep-02 & 29-Sep-02 \\
Anhui & 28-Jul-02 & 1-Sep-02 & Gansu & 7-Sep-02 & 7-Sep-02 \\
Fujian & 26-Jul-02 & 1-Sep-02 & Qinghai & 20-Sep-02 & 1-Jan-03 \\
Jiangxi & 29-Jul-02 & 1-Sep-02 & Ningxia & 7-Nov-02 & 1-Jan-03 \\
Shandong & 28-Sep-02 & 28-Sep-02 & Ningxia & 28-Nov-02 & 5-Dec-02 \\
\hline \hline
\end{tabular}

Note: Though the law was passed at the end 2001, it was only enacted from September 1, 2002. Moreover, in China, each province has its own "Act of Population and Family Planning" based on the "Law of Population and Family Planning" issued by the central government. The central government has clearly stated since the beginning of its family-planning policy that there is no unified rule about family planning, and all provinces should be allowed to have their own policy based on their specific conditions.

The procedure, in practice, is that the central government first issues a law in the National People's Congress, and then each Provincial population and family-planning commission discusses the law and drafts the provincial "Act of Population and Family Planning." The draft is sent to the national population and family-planning commission for review, which may be followed by lobbying and negotiation between the central and provincial governments. Thus, it can take two to three years for the provincial act to be approved and passed in the provincial people's congress and enacted. It's important to point out that the "Act of Population and Family Planning" varies a lot in many detailed articles across provinces. Therefore, in December 2001, there was no way for households to respond to the new "Law of Population and Family Planning" because the specific law in the province had not been drafted at that time, and the decline in the sex ratio before September 2002 should not be attributed to the effect of the " Law of Population and Family Planning." 